\title{
In-Situ High-Energy X-ray Diffraction Study of Austenite Decomposition During Rapid Cooling and Isothermal Holding in Two HSLA Steels
}

\author{
SEN LIN, ULRIKA BORGGREN, ANDREAS STARK, ANNIKA BORGENSTAM, \\ WANGZHONG MU, and PETER HEDSTRÖM
}

\begin{abstract}
In-situ high-energy X-ray diffraction experiments with high temporal resolution during rapid cooling $\left(280{ }^{\circ} \mathrm{C} \mathrm{s}^{-1}\right)$ and isothermal heat treatments (at $450{ }^{\circ} \mathrm{C}, 500{ }^{\circ} \mathrm{C}$, and $550{ }^{\circ} \mathrm{C}$ for 30 minutes) were performed to study austenite decomposition in two commercial high-strength low-alloy steels. The rapid phase transformations occurring in these types of steels are investigated for the first time in-situ, aiding a detailed analysis of the austenite decomposition kinetics. For the low hardenability steel with main composition Fe-0.08C-1.7Mn-0.403$\mathrm{Si}-0.303 \mathrm{Cr}$ in weight percent, austenite decomposition to polygonal ferrite and bainite occurs already during the initial cooling. However, for the high hardenability steel with main composition $\mathrm{Fe}-0.08 \mathrm{C}-1.79 \mathrm{Mn}-0.182 \mathrm{Si}-0.757 \mathrm{Cr}-0.094 \mathrm{Mo}$ in weight percent, the austenite decomposition kinetics is retarded, chiefly by the Mo addition, and therefore mainly bainitic transformation occurs during isothermal holding; the bainitic transformation rate at the isothermal holding is clearly enhanced by lowered temperature from $550{ }^{\circ} \mathrm{C}$ to $500{ }^{\circ} \mathrm{C}$ and 450 ${ }^{\circ} \mathrm{C}$. During prolonged isothermal holding, carbide formation leads to decreased austenite carbon content and promotes continued bainitic ferrite formation. Moreover, at prolonged isothermal holding at higher temperatures some degenerate pearlite form.
\end{abstract}

https://doi.org/10.1007/s11661-021-06192-x

(C) The Author(s) 2021

\section{INTRODUCTION}

High-STRENGTH low-alloy (HSLA) steel sheets are highly valuable in the automotive industry for lightweight and safety applications since they have an excellent combination of high strength, formability, and weldability. Complex-phase HSLA (CP-HSLA) steel often consists of bainite, retained austenite, polygonal ferrite, martensite, and carbides. They experience excellent stretch-flangeability, which is critical in automotive applications, when bainite is the dominant phase. ${ }^{[1-3]}$ Several studies have suggested that the main contributions to the high stretch-flangeability of the bainite constituent is the uniform fine lath structure of the bainite and its ability to balance the hardness difference between ferrite and martensite to hinder crack propagation. $^{[3-6]}$ Retained austenite is also valuable in

SEN LIN, ANNIKA BORGENSTAM, WANGZHONG MU, and PETER HEDSTRÖM are with the Department of Materials Science and Engineering, KTH Royal Institute of Technology, 10044, Stockholm, Sweden. Contact e-mail: senlin@kth.se ULRIKA BORGGREN is with the SSAB AB, 78184, Borlänge, Sweden. ANDREAS STARK is with the Helmholtz Zentrum Geesthacht, Institute of Materials Research, Max Planck Straße 1, 21502 Geesthacht, Germany.

Manuscript submitted February 3, 2020; accepted February 6, 2021.

Article published online March 10, 2021
CP-HSLA steel to improve stretch-flangeability via the transformation-induced plasticity (TRIP) effect. ${ }^{[3,4]}$

Design and manufacturing of these CP-HSLA steels rely on the understanding of the austenite decomposition kinetics to control the bainitic transformation and the carbon diffusion to the retained austenite in order to manipulate the stability of the austenite for optimal contribution of the TRIP effect. The austenite decomposition kinetics is interdependent on the kinetics of multiple phase transformations, and the stability of the retained austenite is not only governed by the carbon diffusion but also the potential carbide precipitation, making the control of optimum properties intricate.

Although CP-HSLA steels have been widely studied in the literature, there is a lack of bulk in-situ characterization studies of the austenite decomposition kinetics. The reason for the lack of studies is most likely the low hardenability of CP-HSLA steels, which means the austenite decomposition, especially the transformation to bainite, is very rapid. Most of the in-situ investigations on the bainitic transformation with neutron diffraction $(\mathrm{ND})^{[7,8]}$ and high-energy X-ray diffraction (HEXRD $)^{[9-13]}$ have focused on model alloys and high-Si steels with very high hardenability, slow decomposition kinetics, and suppressed cementite formation due to the addition of $\mathrm{Si}^{[14,15]}$ With enhanced 
requirements on steel design and optimization, driven by higher requirements in, e.g., automotive applications, it becomes increasingly important to investigate the austenite decomposition kinetics in detail, through, for example, in-situ high-temporal-resolution HEXRD. Deepened insights into the austenite decomposition kinetics, interdependencies of different transformation products, and the evolution of the carbon content of the austenite would be important for further optimization of the microstructure, including the elimination of the undesirable martensite, ${ }^{[16]}$ and tuned TRIP effect ${ }^{[1]}$ by improved control of the generation of a certain austenite stability during heat treatment.

Therefore, in the present work we conduct an in-situ investigation on two commercial CP-HSLA steel sheets. In-situ HEXRD with high data acquisition rate was performed during rapid thermal treatments in a customized quenching-dilatometer setup. Post-mortem microscopy was furthermore applied to supplement the in-situ analysis.

\section{METHODS}

\section{A. Materials}

Two commercial low-carbon HSLA steels were provided by SSAB. The as-received steels were 3-mm-thick hot-rolled sheets, and the chemical compositions of the steels are listed in Table I. To simplify the representation of the overall alloying condition, a carbon equivalent $(\mathrm{CE})$ was evaluated according to the $\mathrm{CE}_{\mathrm{N}}$ formula given in Eq. [1], where the concentration of each element is given in weight percent. ${ }^{[17]}$ The steels are from hereon referred to as high $\mathrm{CE}$ (HCE) and low $\mathrm{CE}$ (LCE). The martensite start temperature, Ms, was calculated using the thermodynamically based (TD) model developed by Stormvinter et al., ${ }^{[18]}$ and the bainite-start temperature, Bs, was calculated using the equation proposed by Leach et al. ${ }^{[19]}$ Moreover, machine learning (ML) models, ${ }^{[20]}$ Ferritico v.2019, was also applied to predict Ms and Bs temperatures. The calculated $\mathrm{CE}_{\mathrm{N}}, \mathrm{Ms}$, and Bs values are also listed in Table I.

$$
\begin{aligned}
\mathrm{CE}_{N}= & C+A(C) \times \\
& {\left[\frac{\mathrm{Si}}{24}+\frac{\mathrm{Mn}}{6}+\frac{\mathrm{Cu}}{15}+\frac{\mathrm{Ni}}{20}+\frac{\mathrm{Cr}+\mathrm{Mo}+\mathrm{Nb}+\mathrm{V}}{5}+5 B\right] . } \\
& A(C)=0.75+0.25 \times \tanh [20(C-0.12)]
\end{aligned}
$$

\section{B. HEXRD Experiment}

HEXRD experiments were performed at the P07-EH3 beamline at PETRA III, Deutsches Elektronen-Synchrotron (DESY), Germany. Figure 1 illustrates the experimental setup, including a customized Bähr DIL805 A/D quenching-dilatometer. The samples were cut along the transverse plane of the hot-rolled sheet with a dimension of $10 \times 3 \times 1.5 \mathrm{~mm}^{3}$ and were fixed between two quartz rods. One of the rods was the pushrod connected to the linear variable differential transducer (LVDT) that determines the length variation of the sample during the heat treatment. The samples were heated by an induction coil and quenched by helium gas flow. The temperature was recorded by a type-S thermocouple spot-welded on the sample surface. The position of the thermocouple was $1 \mathrm{~mm}$ away from the center of the long direction of the sample, i.e., close to the gauge volume measured by HEXRD. The applied thermal cycle included heating at a rate of $10{ }^{\circ} \mathrm{C} \mathrm{s}^{-1}$ to $900{ }^{\circ} \mathrm{C}$ and holding for 600 seconds to form austenite, followed by quenching at a rate of $280{ }^{\circ} \mathrm{C} \mathrm{s}^{-1}$ to different temperatures $\left(450{ }^{\circ} \mathrm{C}, 500{ }^{\circ} \mathrm{C}, 550{ }^{\circ} \mathrm{C}\right)$ for isothermal heat treatment for 1800 seconds. When quenching to below $700{ }^{\circ} \mathrm{C}$, the cooling rate slowed down to 150 to $200{ }^{\circ} \mathrm{C} \mathrm{s}^{-1}$. The heat treatment ended with a final quenching $\left(150{ }^{\circ} \mathrm{C} \mathrm{s}^{-1}\right)$ to room temperature. The applied thermal cycles are illustrated in Figure 2.

The X-ray energy used was $100 \mathrm{keV}(\lambda=0.124 \AA)$ and the beam size was $0.5 \times 0.5 \mathrm{~mm}^{2}$. The diffraction patterns were collected by an area detector (PerkinElmer XRD 1621) located approximately $1550 \mathrm{~mm}$ behind the specimens (Figure 1). The setup geometry was calibrated with a NIST (National Institute of Standards and Technology) standard $\mathrm{LaB}_{6}$ powder (SRM 660b). Two data acquisition modes were applied throughout each heat treatment cycle: (i) Fast mode with an acquisition rate of $0.1 \mathrm{~s} /$ pattern was executed during initial quenching and the first 300 seconds of the isothermal holding, and (ii) slow mode with an acquisition rate of $3 \mathrm{~s} /$ pattern was executed during heating, austenitization, isothermal holding after 300 seconds and final quenching.

Calibration of the experimental parameters and integration of the two-dimensional diffraction patterns were conducted using the Fit2D software. ${ }^{[21,22]}$ The $\gamma 111$ and $\alpha 110$ peaks were fitted using a pseudo-Voigt function in LIPRAS. ${ }^{[23]}$ The phase fractions of austenite $\left(V_{\gamma}\right)$ and ferrite/bainite/martensite $\left(V_{\alpha}\right)$ were calculated using the direct comparison method (Eq. 2) ${ }^{[24]}$ :

$$
V_{\gamma}=\frac{\frac{1}{q} \sum_{j=1}^{q} I_{\gamma j} / R_{\gamma j}}{\frac{1}{q} \sum_{j=1}^{q} I_{\gamma j} / R_{\gamma j}+\frac{1}{p} \sum_{i=1}^{p} I_{\alpha i} / R_{\alpha i}},
$$

where $I_{\gamma j}$ and $I_{\alpha i}$ are the measured intensities of the $j$ th fcc reflection and $i$ th bcc reflection, respectively; $R_{\gamma j}$ and $R_{\alpha i}$ are their corresponding theoretical intensities. The measured intensity can be directly obtained from the one-dimensional diffraction line profile as the integrated intensity of each peak. The theoretical intensity can be calculated from

$$
R_{i}^{\mathrm{hk} l}=\left(\frac{1}{v^{2}}\right)\left[|F|^{2} p\left(\frac{1+\cos ^{2} 2 \theta}{\sin ^{2} \theta \cos \theta}\right)\right]\left(e^{-2 M}\right),
$$

where $v$ is the volume of the unit cell, $F$ is the structure factor of a given $h k 1$ reflection, $p$ is the multiplicity factor of the corresponding reflection, $\left(1+\cos ^{2} 2 \theta\right) /\left(\sin ^{2} \theta \cos \theta\right)$ is the Lorentz Polarization factor where $\theta$ is the diffraction angle, and $e^{-2 M}$ is the Debye-Waller factor. 
Table I. Chemical Composition (Wt Pct, Fe Balance) and Characteristic Temperatures $\left({ }^{\circ} \mathrm{C}\right)$ of the Studied Steels

\begin{tabular}{lccccccccccc}
\hline & $\mathrm{C}$ & $\mathrm{Si}$ & $\mathrm{Mn}$ & $\mathrm{Cr}$ & $\mathrm{Ni}$ & $\mathrm{Mo}$ & $\mathrm{Al}$ & $\mathrm{Cu}$ & $\mathrm{Nb}$ & $\mathrm{V}$ \\
\hline HCE & 0.08 & 0.182 & 1.79 & 0.757 & 0.151 & 0.094 & 0.044 & 0.165 & 0.032 & 0.013 \\
LCE & 0.08 & 0.403 & 1.7 & 0.303 & 0.201 & 0.005 & 0.038 & 0.011 & 0 & 0.015 \\
\hline & $\mathrm{Ti}$ & $\mathrm{P}$ & $\mathrm{S}$ & $\mathrm{N}$ & $\mathrm{B}$ & $\mathrm{CE}$ & $\mathrm{Ms}-\mathrm{TD}$ & $\mathrm{M}$-ML & Bs-TD & Bs-ML \\
\hline HCE & 0.054 & 0.016 & 0.002 & 0.0056 & 0.0003 & 0.38 & 384 & 409 & 618 & 590 \\
LCE & 0.08 & 0.01 & 0.002 & 0.005 & 0.0003 & 0.3 & 400 & 420 & 648 & 590 \\
\hline
\end{tabular}

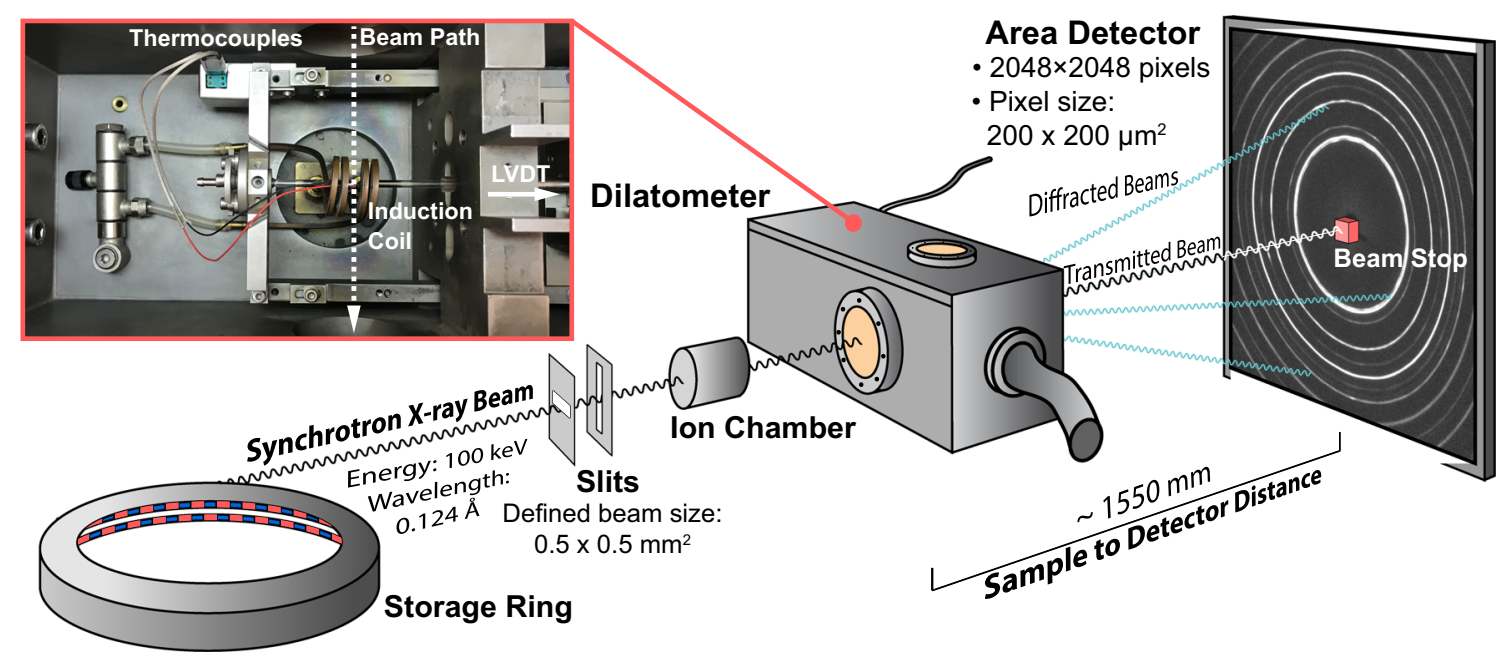

Fig. 1-Schematic illustration of the in-situ X-ray diffraction experimental setup with a customized quenching-dilatometer at PETRA III, P07 beamline.

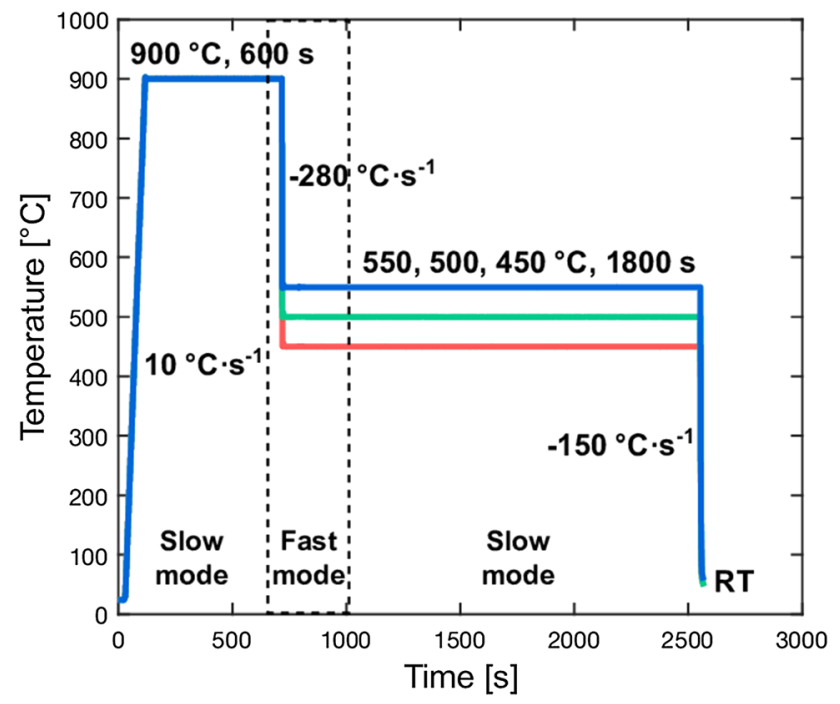

Fig. 2-Heat treatment and data acquisition schemes. Fast data acquisition mode (area enclosed by dashed line) was used to study the early stage of the transformation in detail.

The carbon content in the retained austenite $\left(C_{\gamma}\right)$ can be calculated using
Table II. The Coefficient of Thermal Expansion for fec and bec $\left(K^{-1}\right)$

\begin{tabular}{lcc}
\hline & $\gamma 111$ & $\alpha 110$ \\
\hline HCE & $22.3 \times 10^{-6}$ & $16.0 \times 10^{-6}$ \\
LCE & $21.5 \times 10^{-6}$ & $15.7 \times 10^{-6}$ \\
\hline
\end{tabular}

$$
C_{\gamma}=\frac{\Delta a}{k_{C}}+C_{0},
$$

where $\Delta a=a-a_{0}$ is the relative lattice parameter variation, $a_{0}$ is the austenite lattice parameter at the start of the isothermal transformation, $k_{C}=$ $0.0453 \AA /$ wt pct $C$ is the austenite expansion coefficient due to carbon obtained from van Dijk et al., ${ }^{[25]}$ and $C_{0}=0.08 \mathrm{wt}$ pct is the nominal carbon content of the material. The lattice parameters obtained from $\gamma 111$ and $\alpha 110$ are normalized to room temperature values using the coefficient of thermal expansion $C T E=(1 / a)(\mathrm{d} a / \mathrm{d} T) \cdot{ }^{[26]}$ The CTEs are calculated using the $\gamma 111$ and $\alpha 110$ peaks from HEXRD data recorded during the heating stage and initial quenching and listed 
in Table II. The values are in good agreement with References 10 and 27.

\section{Microscopy}

The samples were characterized after HEXRD experiments using a field-emission scanning electron microscope JEOL 7800F. Samples were polished down to 0.05 $\mu \mathrm{m}$ alumina suspension. For imaging, polished samples were etched with $4 \mathrm{~g}$ picric acid $+1 \mathrm{~mL}$ hydrochloric acid $+100 \mathrm{~mL}$ ethanol. Secondary electron imaging (SE), energy dispersive X-ray spectroscopy (EDS), and electron backscatter diffraction (EBSD) were performed. SE images were taken at $7 \mathrm{~mm}$ working distance and with $10 \mathrm{kV}$ acceleration voltage; EDS analyses were performed at $10 \mathrm{~mm}$ working distance and $15 \mathrm{kV}$ acceleration voltage; and EBSD data were collected using $15 \mathrm{kV}$ acceleration voltage at $20 \mathrm{~mm}$ working distance and using $50 \mathrm{~nm}$ step size.

Post-processing and analyses of EBSD data were performed using the MATLAB-based Toolbox MTEX. ${ }^{[28]}$ Separation of high-angle and low-angle boundaries is defined by a $15 \mathrm{deg}$ misorientation threshold. Grains smaller than 5 pixels were removed and noise/dead pixels were filtered out using the half quadratic filter method. ${ }^{[28]}$ Three criteria were applied in sequence to separate polygonal ferrite from bainitic ferrite $^{[26,29]}$ : (1) grain orientation spread (GOS): structures with GOS $<1.5 \mathrm{deg}$, (2) geometric aspect ratio (AR): $\mathrm{AR}<2.5$, and (3) grain radii $<\sim 1 \mu \mathrm{m}$ for $\mathrm{HCE}$ and $<\sim 1.5 \mu \mathrm{m}$ for LCE were identified as polygonal ferrite. The grain size criterion for the two alloys was decided based on estimations from SE images.

\section{Simulations}

Formation of polygonal ferrite was simulated using DICTRA with the TCFE9 and MOBFE4 database. ${ }^{[30,31]}$ Major alloying elements, Fe, C, Mn, Si, Cr, and $\mathrm{Mo}$, were considered in the simulations. Transformation-start temperature and cooling rates were set to the experimentally determined values. Austenite domain size was set to $3.5 \mu \mathrm{m}$, which is the estimated radius of the prior austenite grains as determined from the SE images in Fig. 7. Ferrite was introduced as inactive so that the initial equilibrium condition at the interface can be determined automatically. The multi-phase homogenization model ${ }^{[32]}$ was used under the assumption of local equilibrium (LE) and paraequilibrium (PE) conditions.

\section{RESULTS}

Figures 3(a) and (b) show the dilatometric curves recorded during the in-situ HEXRD measurements. For convenience, the samples are named HCE450, HCE500, HCE550, LCE450, LCE500, LCE550 relating to the different isothermal heat treatment temperatures for the two different alloys. The two alloys, HCEs and LCEs, have different austenite decomposition behaviors, which are reflected in the derivative of the dilatometric curve during the quenching (Figures 3(c) and (d)). The austenite started to decompose already during the initial quenching in both HCEs and LCEs, see Figures 3(a) and (b). However, accurate transformation-start temperatures are difficult to determine from the dilatometry curves. Furthermore, the non-linear characteristics of the derivative at higher temperatures $\left(800{ }^{\circ} \mathrm{C}\right.$ to $\left.900{ }^{\circ} \mathrm{C}\right)$ suggest the temperature is not homogeneous throughout the samples, see Figures 3(c) and (d).

Figures 4(a) and (b) show the bcc volume fraction evolution in HCEs and LCEs, respectively. The curves represent the total amount of polygonal ferrite, pearlitic ferrite, bainitic ferrite, and martensite. The transformation kinetics is rapid in both alloys, approaching completion within 10 seconds. The temperature that the austenite decomposition can be detected initially by HEXRD is shown in Figures 4(c) and (d), which is around $660{ }^{\circ} \mathrm{C}$ for HCEs (Figure 4(a)) and around 700 ${ }^{\circ} \mathrm{C}$ for LCEs (Figure 4(b)). The volume fraction of bcc formed at different heat treatment stages is listed in Table III. As can be seen, austenite in LCE is more susceptible towards decomposition than in HCE. During initial quenching, a higher fraction of austenite has already decomposed in LCE as compared to HCE samples above $\mathrm{Bs}$, as calculated according to both Bs-TD and Bs-ML models. At the isothermal stage, the transformation is more rapid at lower isothermal temperatures and reaches a higher final degree of austenite decomposition. At the end of the isothermal holding, nearly all the austenite in LCEs has decomposed. In contrast, small fractions of austenite remain in HCEs after the isothermal holding which partially transforms into martensite during final quenching to room temperature. This is most evident in HCE550 where a volume fraction of about 0.1 martensite forms upon final cooling.

The carbon content in the retained austenite is calculated using Eq. [4] under the assumption that the lattice parameter is primarily affected by the carbon content. EDS mapping and point detections (see the Supplementary Figures S-1 and 2, and Table S-I) show non-detectable segregation of the substitutional elements in all samples and the weight percentage (Supplementary Table S-I) is close to the nominal values. It should be mentioned that initially the fcc peaks become slightly asymmetric at the onset of transformation (Figures 5(b) and (e)), which might be an indication of local chemical composition variations. However, the asymmetry is weak and only existed for a few seconds (Figures 5(c) and (d)), and thus its influence on the evaluated overall chemical composition is minor and assumed to be negligible during peak fitting.

The carbon content in retained austenite is shown in Figures 6(a) and (b). Initially, the carbon content in the retained austenite barely changes. After 1 to 2 seconds, the carbon content in the austenite starts to increase until the transformation reaches cessation. In LCEs, it starts earlier and thus at higher temperatures than in HCEs. The carbon enrichment of austenite is less prominent at higher isothermal temperature hold. Finally, the carbon content starts to continuously decrease in all samples except for HCE550 where there 


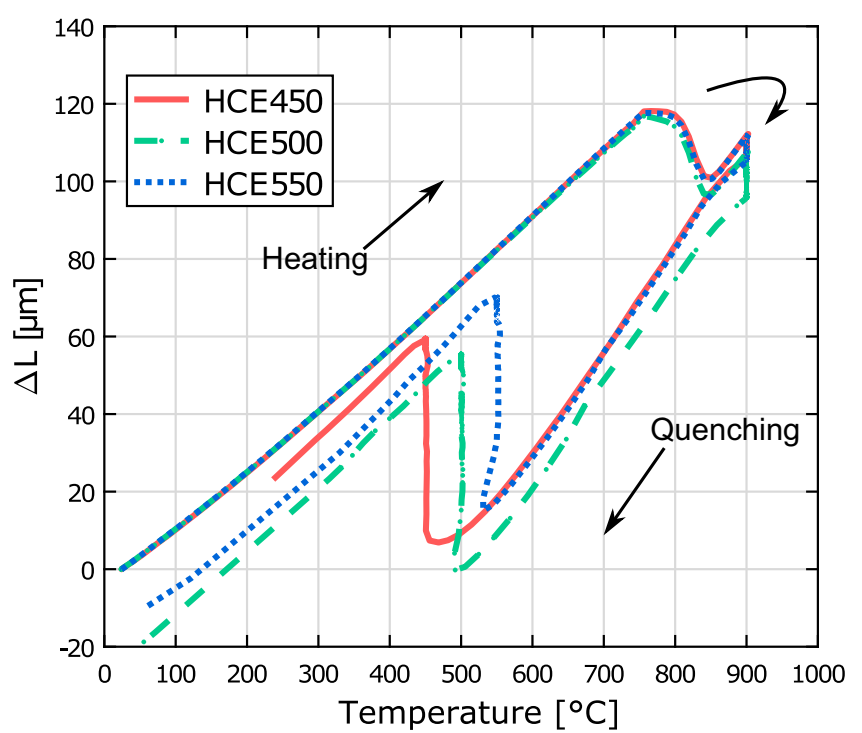

(a)

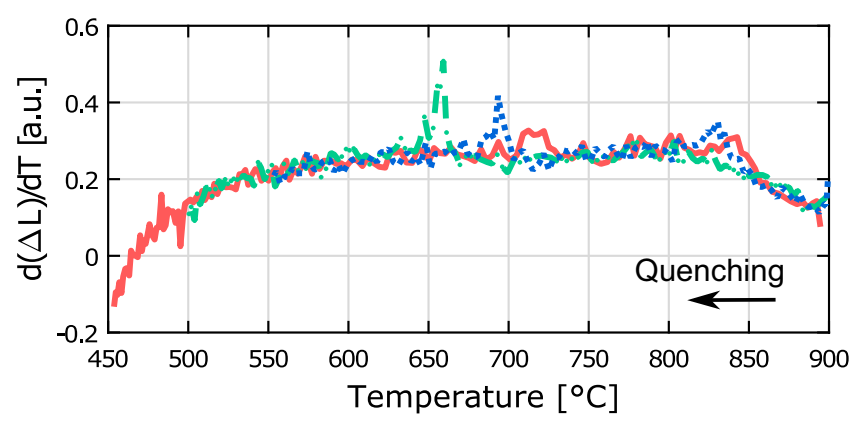

(c)

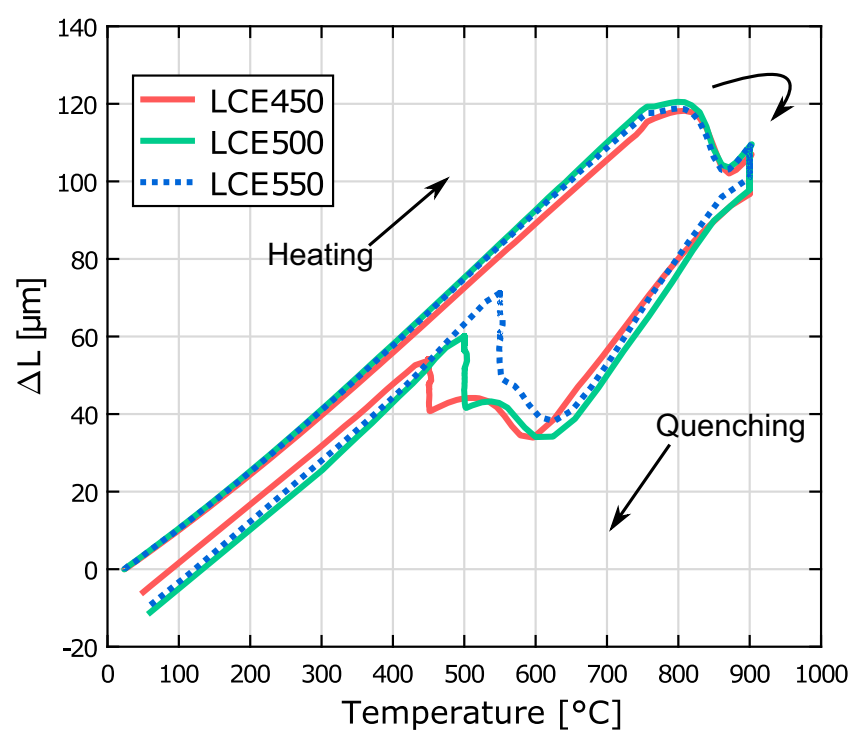

(b)

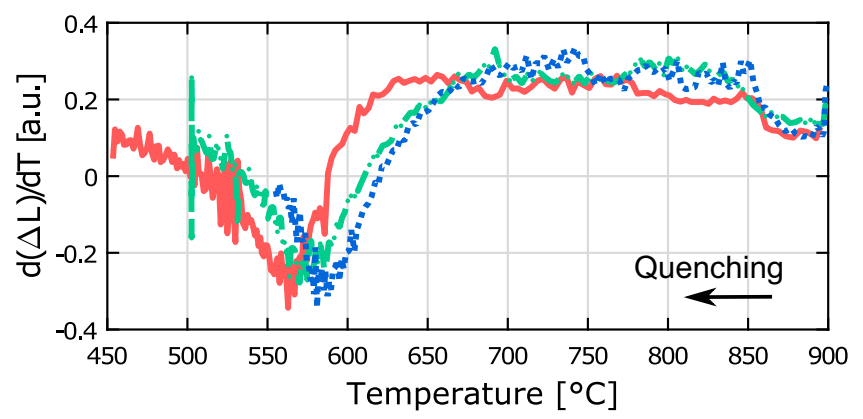

(d)

Fig. 3-Dilatometric curves recorded during in-situ HEXRD experiments for (a) HCEs, (b) LCEs, and the first derivatives of the dilatometric curve at initial quenching stage from $900{ }^{\circ} \mathrm{C}$ to $450{ }^{\circ} \mathrm{C}$ for $(c) \mathrm{HCEs},(d)$ LCEs.

is a slight increase. On the other hand, the variation of the ferrite lattice parameter is less clear due to the minor influence of carbon on the lattice parameter and also because the changes are obscured by the observed temperature fluctuations (Figures 6(c) and (d)). Anyhow, there is a general decreasing trend of the lattice parameter with time; the spikes momentarily disrupting this trend are most likely caused by the thermal fluctuations shown in Figures 6(e) and (f).

Figure 7 shows the SE images of the final microstructures. All samples mainly consist of bainitic ferrite (BF), though carbides (C) and polygonal ferrite (PF) are observed and in some samples also degenerate pearlite (DP) and martensite (MA). Carbides are observed between bainitic ferrite laths, formed during the bainitic transformation, but also at high-angle boundaries. Polygonal ferrite is also found at the prior austenite grain boundaries, for example in Figures 7(a), (d), and (f). It should be noted that in the present study, bainitic ferrite and Widmanstätten ferrite are not distinguished from each other, since both are acicular structures. Furthermore, HCE and LCE have low nominal C content and the acicular structure forms primarily without any carbide formation during the initial transformation.

The detailed features of HCEs are exemplified in Figure 8 for HCE450 and HCE550 using EBSD band contrast maps overlaid with inverse pole figure (IPF) coloring. After isothermal holding at low temperature, e.g., HCE at $450{ }^{\circ} \mathrm{C}$ (Figure 8(a)), the bainite packets can be readily distinguished from the boundary misorientation map. The inset phase map indicates that the retained austenite is located at the high-angle boundaries. It is difficult to discern small retained austenite and carbides from SE and EBSD results, but it appears as if the carbides mainly are formed from carbon enriched austenite, and thus they share the same locations, for example, they can be observed between two impinged bainite packets within a prior austenite grain as indicated by the two arrows marked with ' $\mathrm{BF}$ ' in Figure 7(a). At higher isothermal holding temperatures for $\mathrm{HCE}$, the boundaries between bainitic ferrite packets are less clear, as indicated in Figure 8(b). Furthermore, at the higher isothermal holding temperatures, degenerate pearlite appears, as shown in, e.g., Figure 7(b). In the EBSD results for HCE550, several 


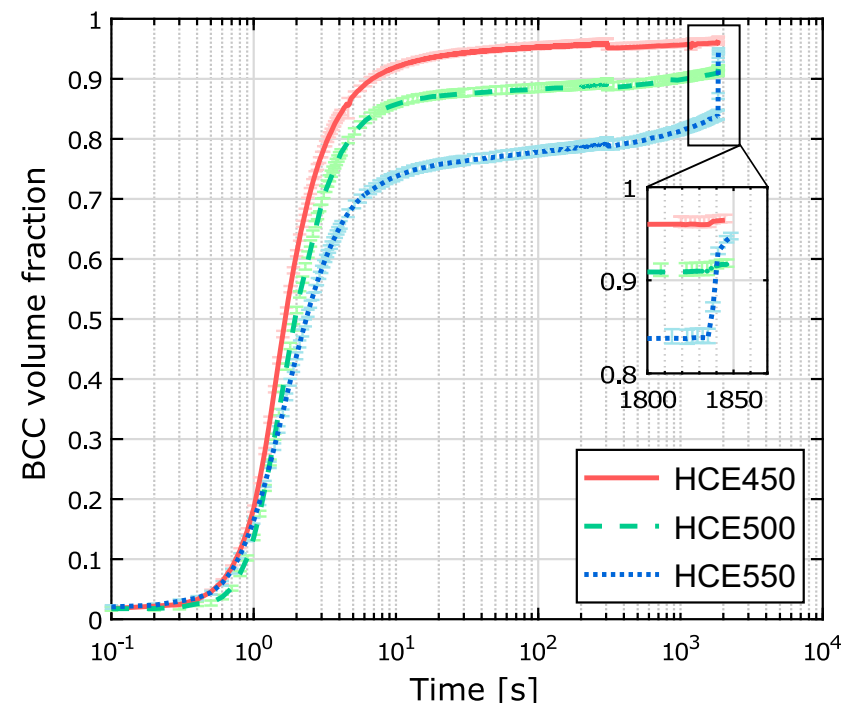

(a)

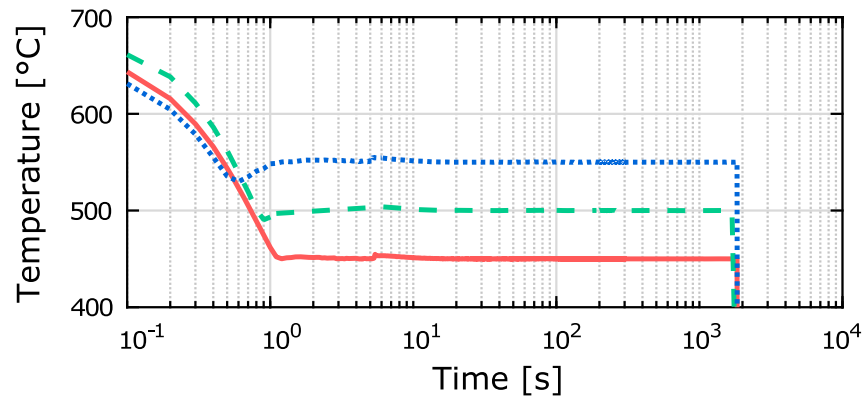

(c)

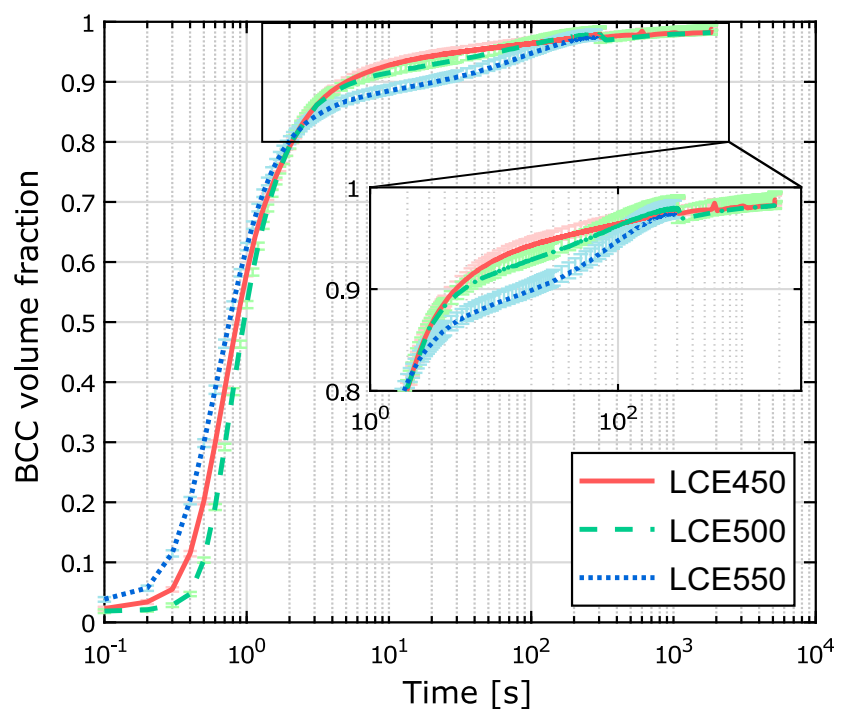

(b)

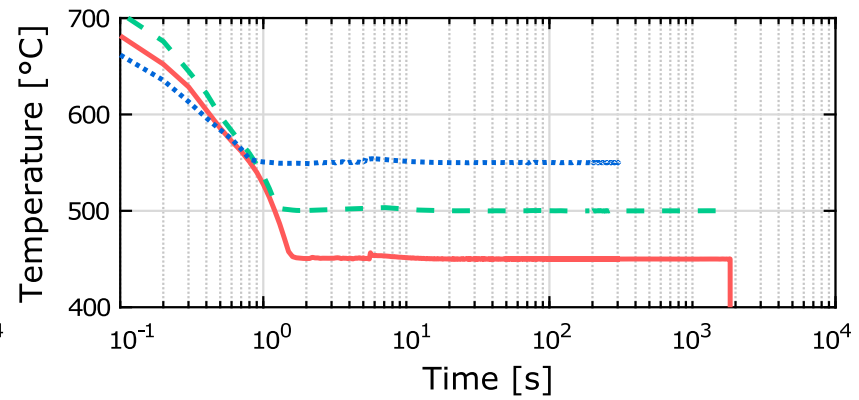

(d)

Fig. 4-Bcc phase fraction evolution during the heat treatment for $(a)$ HCEs, $(b)$ LCEs; $(c)$ and $(d)$ are the corresponding temperature profiles recorded for each experiment of HCEs and LCEs, respectively. Note that the drops for the three samples in (a) at the 300th second is due to the data collection shifting from fast mode to slow mode.

Table III. Volume Fractions of bcc Phases Formed at Different Heat Treatment Stages (Volume Fraction of Polygonal Ferrite Formed During Initial Quenching Determined by HEXRD Results and Assuming Bs to be Either According to Bs-ML Values in $V_{\mathrm{PF}(\mathrm{Bs}-\mathrm{ML})}^{\mathrm{HEXRD}}$ or According to Bs-TD in $V_{\mathrm{PF}(\mathrm{Bs}-\mathrm{TD})}^{\mathrm{HEXRD}} ; V_{\mathrm{PF}}^{\mathrm{EBSD}}$ is the Polygonal Ferrite Fraction Determined by the EBSD Method;

$V_{\mathrm{PF}+\mathrm{BF}}^{\mathrm{HEX}}$ is the Total Amount of bec Phases Formed During Initial Quenching Including Polygonal Ferrite and Bainitic Ferrite; $V_{M A}^{\mathrm{HEXRD}}$ is the Amount of Martensite Formed During Final Quenching

\begin{tabular}{|c|c|c|c|c|c|c|}
\hline & \multirow[b]{2}{*}{ Cooling Rate $\left({ }^{\circ} \mathrm{C} \mathrm{s}^{-1}\right)$} & \multicolumn{4}{|c|}{ Initial Quenching } & \multirow{2}{*}{$\begin{array}{c}\text { Final Quenching } \\
V_{\text {MAXRD }}^{\mathrm{HEXRD}} \\
\end{array}$} \\
\hline & & $V_{\mathrm{PF}(\mathrm{Bs}-\mathrm{ML})}^{\mathrm{HEXRD}}$ & $V_{\mathrm{PF}(\mathrm{Bs}-\mathrm{TD})}^{\mathrm{HEXRD}}$ & $V_{\mathrm{PF}}^{\mathrm{EBSD}}$ & $V_{\mathrm{PF}+\mathrm{BF}}^{\mathrm{HEXRD}}$ & \\
\hline HCE450 & 192.5 & 0.024 & 0.022 & 0.051 & 0.232 & 0.004 \\
\hline HCE500 & 201.5 & 0.025 & 0.020 & 0.041 & 0.076 & 0.007 \\
\hline HCE550 & 192 & 0.027 & 0.023 & 0.052 & 0.035 & 0.108 \\
\hline LCE450 & 154 & 0.183 & 0.034 & 0.106 & 0.742 & 0 \\
\hline LCE500 & 206.5 & 0.152 & 0.029 & 0.109 & 0.661 & 0 \\
\hline LCE550 & 140 & 0.253 & 0.048 & 0.136 & 0.529 & 0 \\
\hline
\end{tabular}

areas with martensite and some retained austenite (MA) are also seen (Figure $8($ b)) .

The microstructures of LCEs are similar to HCE450 and HCE500. Bainite packet boundaries are less clear in LCE samples as compared to HCEs. In some regions, bainite can only be identified by the carbides aligning in one direction, for example in Figure $7(\mathrm{~d})$. Degenerate pearlite is also observed at the high temperatures in LCE, for example in LCE500 and LCE550 (Figures 7(e) and (f)).

Misorientations with respect to mean misorientation of each grain and distribution of polygonal ferrite grains are presented in Figure 9. In Figures 9(a) through (c) and (g) through (i), bainite packets can be recognized by 


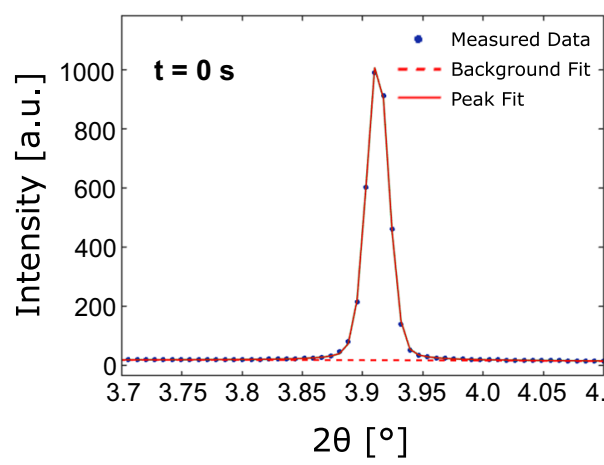

(a)

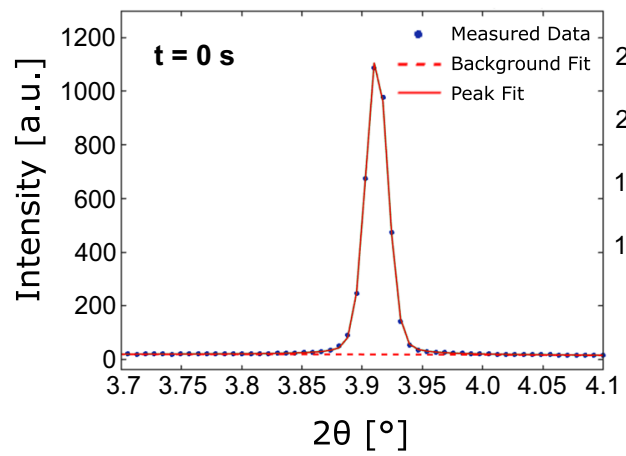

(d)

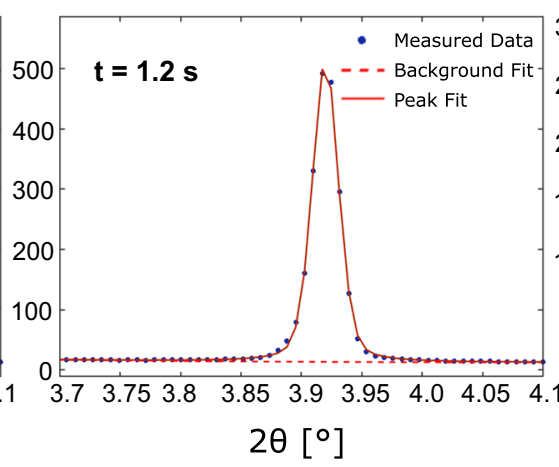

(b)

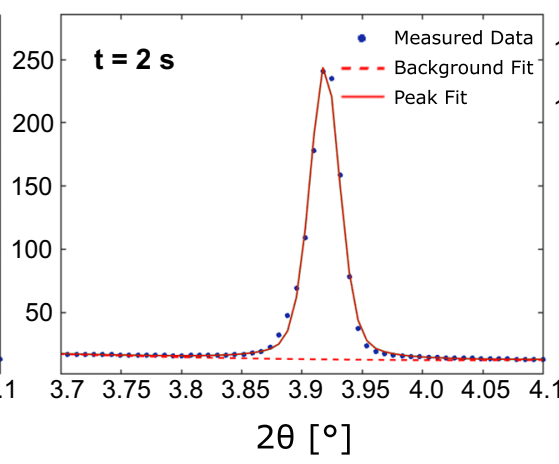

(e)

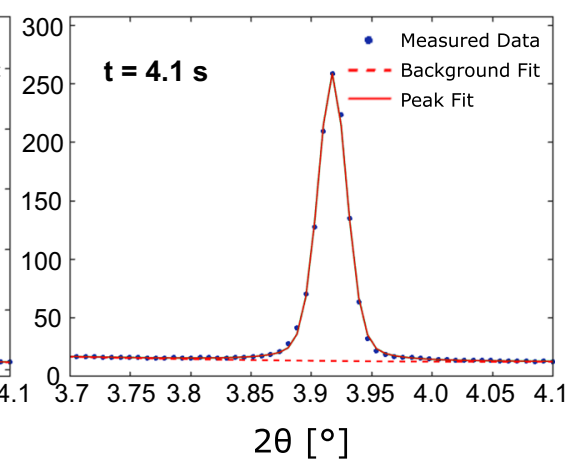

(c)

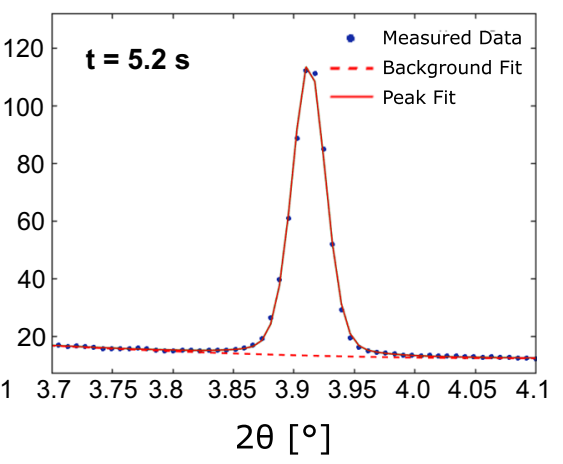

(f)

Fig. 5-HEXRD line profile of fcc 200 peaks of ( $a$ through $c$ ) HCE550 and ( $d$ through $f$ ) LCE550 at different times. The blue dots are the experimental values whereas the red lines are the fitting result using the pseudo-Voigt function.

the varying colors between white and red within the reconstructed grains. The grain misorientations and high-angle boundaries decrease with increasing isothermal holding temperature. In general, HCEs have higher grain misorientations than LCEs. More polygonal ferrite can be found in LCEs by comparing Figures 9(d) through (f) (HCE) and (j) through (l) (LCE). The fraction of polygonal ferrite in the different samples is listed in Table III.

The misorientation frequency is plotted in Figure 10. Two peaks around $53^{\circ}$ and $60^{\circ}$ in all samples are common for bainitic ferrite and suggest the Kurdjumov-Sachs orientation relationship. ${ }^{[3]}$ These peaks in HCE samples decrease with increasing isothermal temperature and are stronger than in LCE samples. For LCE samples, the frequency between 20 and 40 deg is slightly higher, which indicates a higher volume faction of polygonal ferrite. ${ }^{[33,34]}$ The very high peak below 5 deg is associated with the bainitic ferrite lath boundaries, ${ }^{[33]}$ and to some extent, the angular resolution in the applied EBSD measurements, which is about $1 \mathrm{deg}$.

The DICTRA simulation in Figure 11 shows the formation of polygonal ferrite, where the interface position in Figures 11(a) and (b) represents the transformation progress and can be regarded as the size of polygonal ferrite. The interface condition obtained from the simulation under LE assumption is negligible partitioning local equilibrium (NPLE). Under both NPLE and PE conditions, LCE transforms more rapidly than HCE. Comparing simulations and the experimentally evaluated size of polygonal ferrite, it is found that the transformation to polygonal ferrite seems to occur closer to PE than NPLE condition. The experimental size determinations are $\sim 1 \mu \mathrm{m}$ for $\mathrm{HCE}$ and $\sim 1.5 \mu \mathrm{m}$ for LCE (Figures 7(a) and (d)), whereas simulations using $\mathrm{PE}$ condition give $\sim 1.5 \mu \mathrm{m}$ for $\mathrm{HCE}$ and 1.8 to $2.1 \mu \mathrm{m}$ for LCE, while NPLE condition give $0.5 \mu \mathrm{m}$ for HCE and 0.7 to $0.8 \mu \mathrm{m}$ for LCE. Figure 11(c) shows the carbon concentration profile across the ferrite/austenite interface under PE condition. With decreasing temperature, the height of the spike increases but the width decreases. At the same temperature, the width of the spike in LCE450 is around $298 \mathrm{~nm}$, which is wider than $175 \mathrm{~nm}$ for HCE450. Note that the cooling conditions set for each simulation are different in order to replicate the HEXRD experimental conditions; therefore, the diffusion time varies when reaching the same temperature between different simulations.

\section{DISCUSSION}

\section{A. In-Situ HEXRD Measurements on Austenite Decomposition}

The accuracy of the lattice parameter determination is affected by data processing error including integration and peak fitting ${ }^{[10]}$ and can be determined by comparing the calculated reference $\mathrm{LaB}_{6}$ lattice parameter with its NIST certificate value. ${ }^{[35]}$ In this study, the data 
(a)

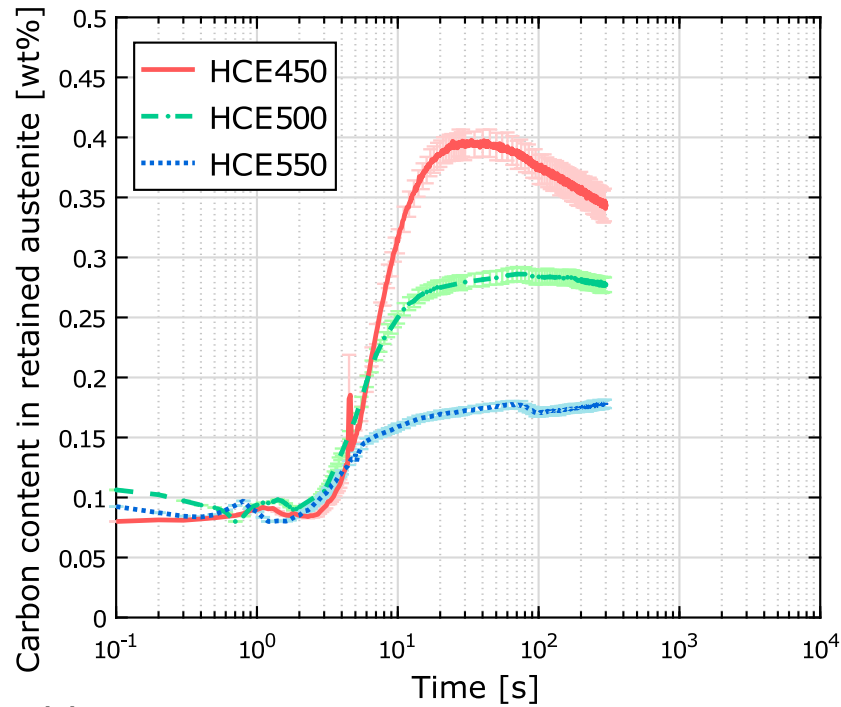

(c)
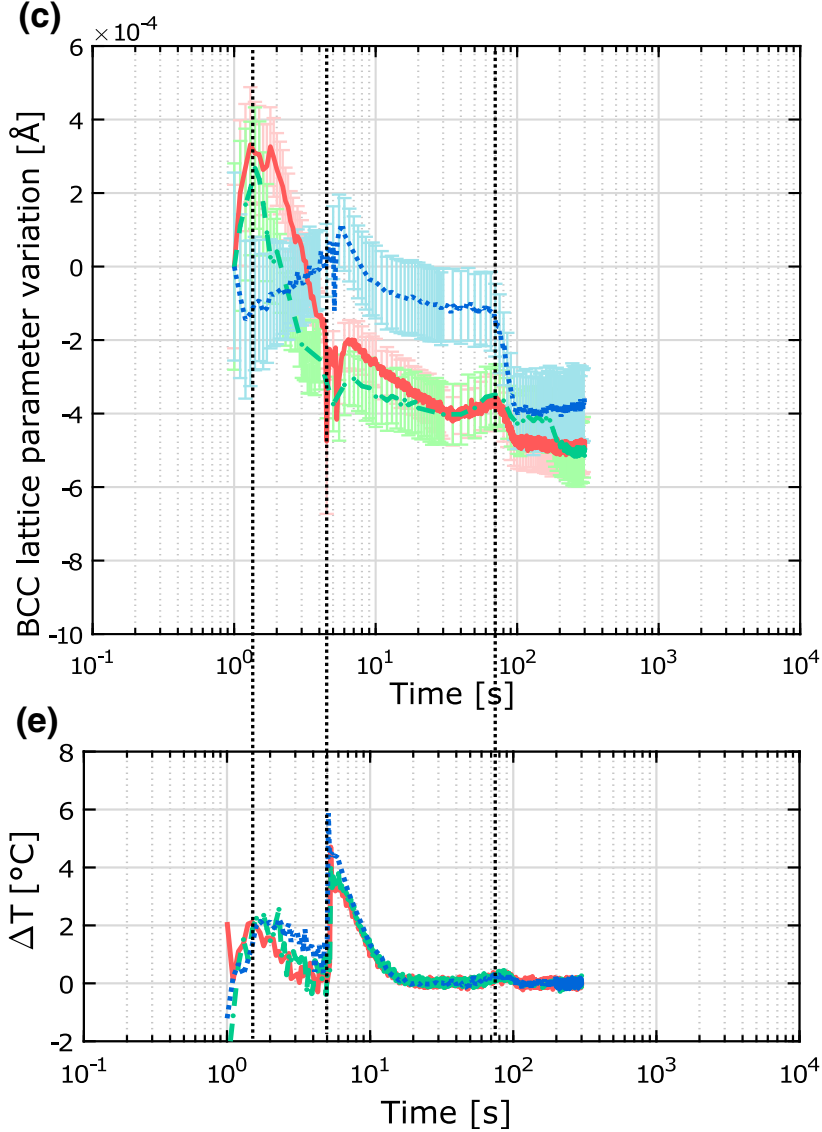

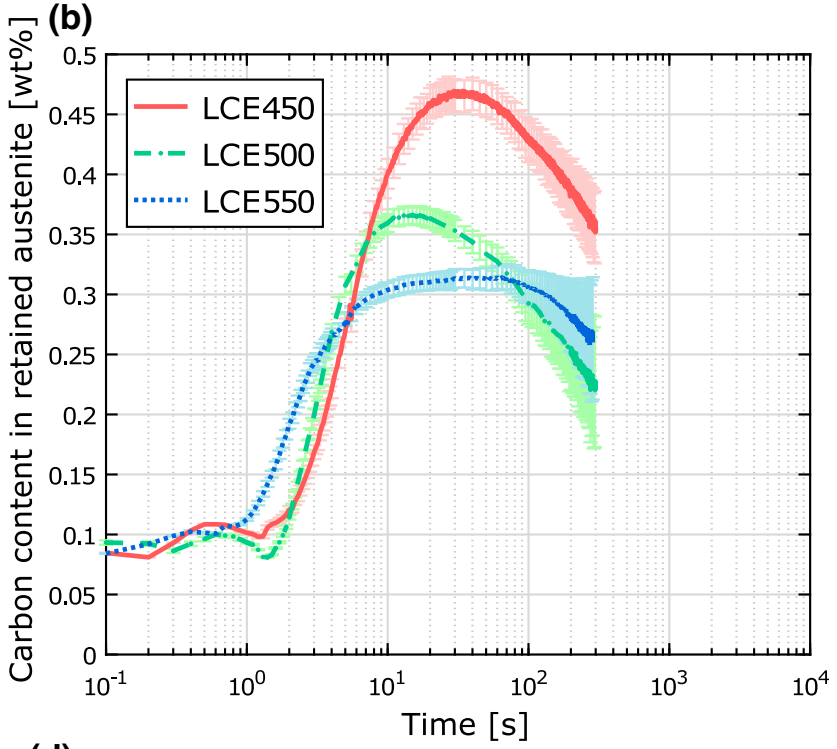

(d)
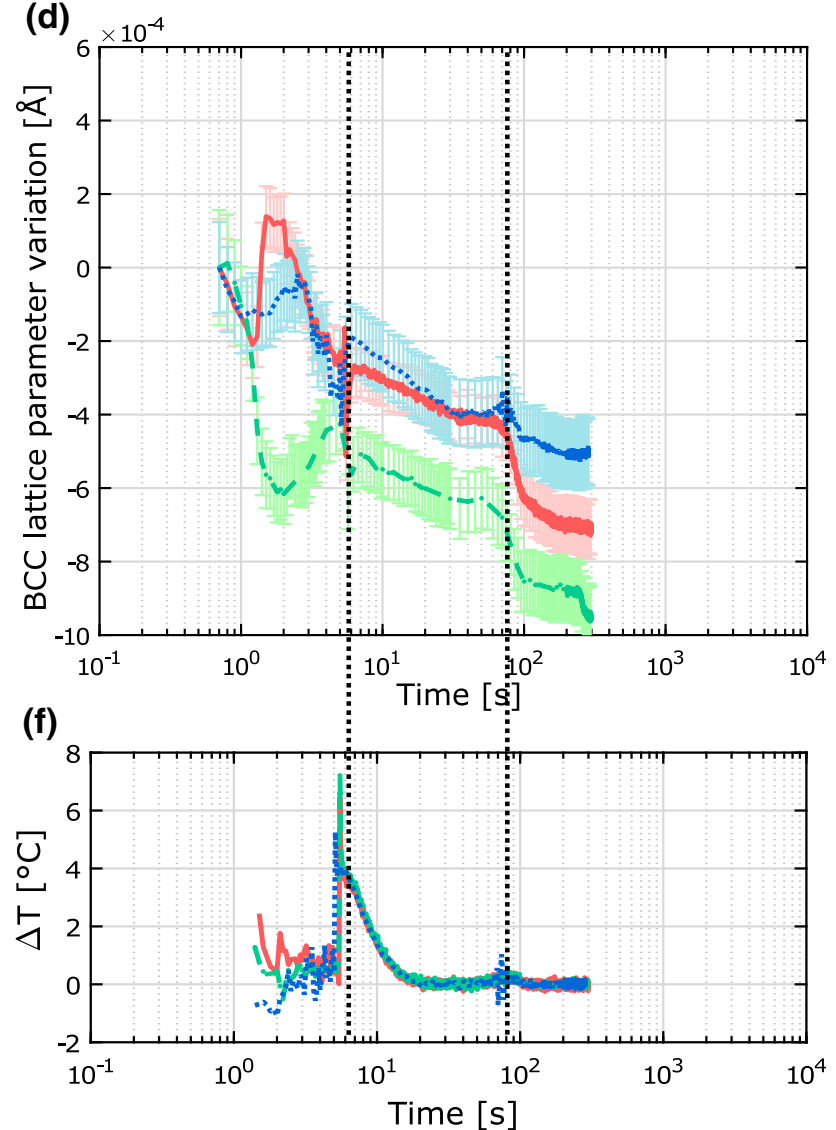

Fig. 6-Carbon content variation in the retained austenite during the heat treatment in $(a)$ HCEs, $(b)$ LCEs, and the lattice parameter variation of the bcc phases in $(c)$ HCEs, $(d)$ LCEs; $(e)$ and $(f)$ are the temperature variations corresponding to each experiment of HCEs and LCEs, respectively.

processing error is $\pm 1.1 \times 10^{-3} \AA$, which is 10 times weaker than the lattice parameter variation of austenite (average $\sim 1.0 \times 10^{-2} \AA$ ). Therefore, the determined lattice parameter variation in austenite can be regarded as a result of change in temperature and phase composition. In order to obtain changes in phase composition, the temperature effect is deconvoluted using CTE. However, the temperature effect cannot be fully 


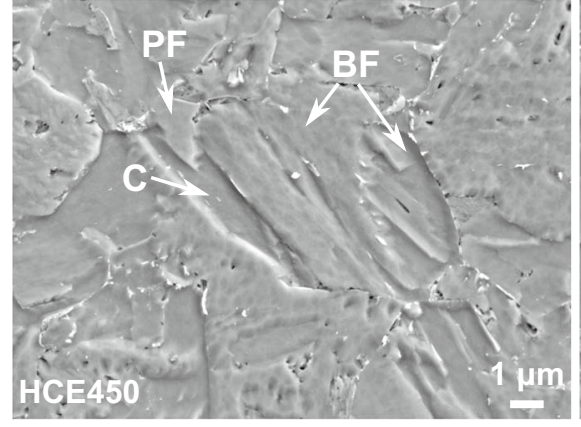

(a)

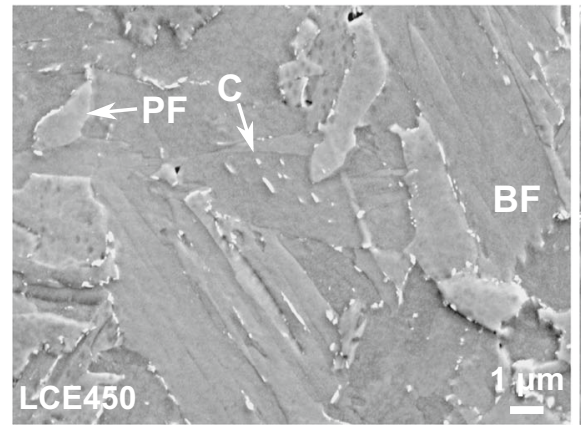

(d)

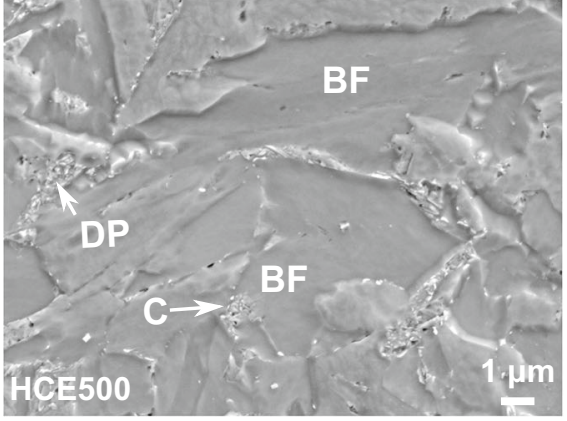

(b)

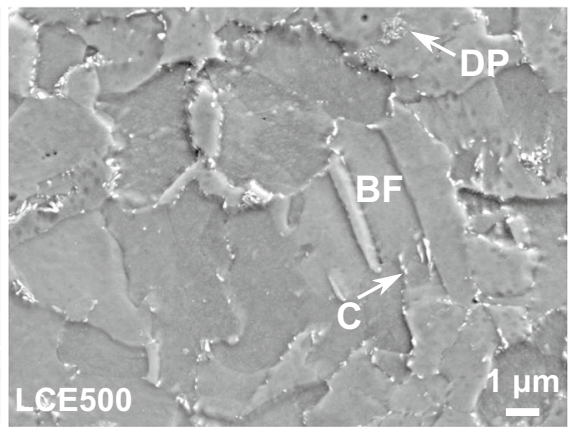

(e)

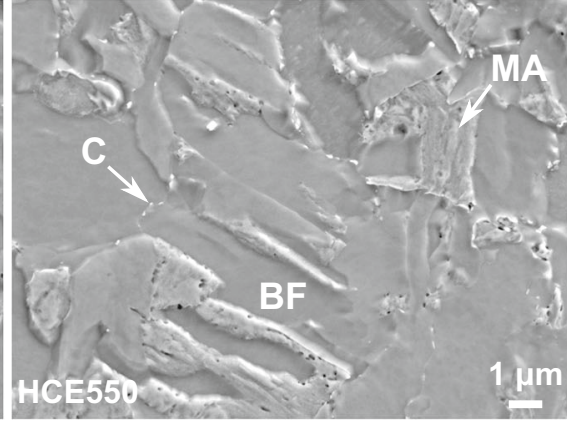

(c)

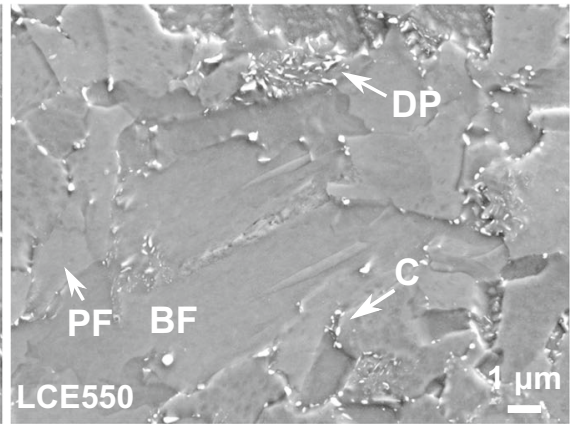

(f)

Fig. 7-Final microstructures. ( $a$ to $c$ ) HCE samples heat-treated at $450{ }^{\circ} \mathrm{C}, 500{ }^{\circ} \mathrm{C}, 550{ }^{\circ} \mathrm{C}$, respectively; $(d$ to $f)$ LCE samples heat-treated at 450 ${ }^{\circ} \mathrm{C}, 500{ }^{\circ} \mathrm{C}, 550{ }^{\circ} \mathrm{C}$, respectively. $B F$ bainitic ferrite, $P F$ polygonal ferrite, $C$ carbides, $D P$ degenerate pearlite, $M A$ martensite/austenite constituent.
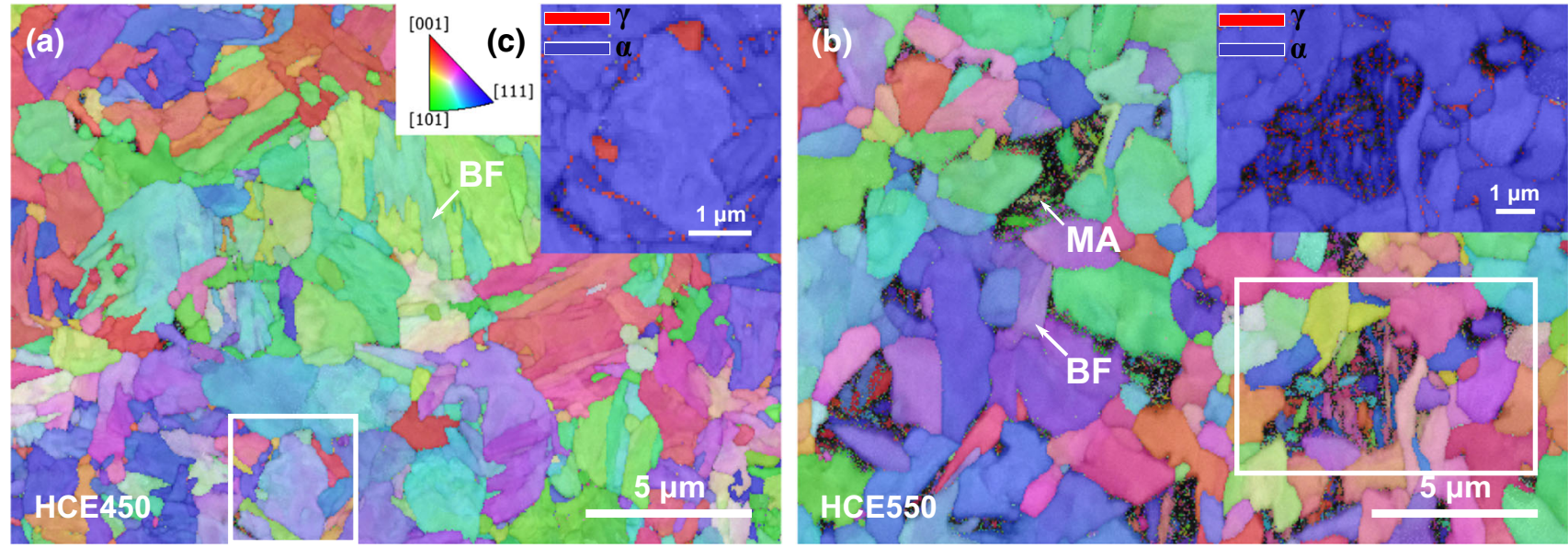

Fig. 8-EBSD band contrast maps with IPF coloring for $(a)$ HCE450, $(b)$ HCE550; the insets are the phase maps of the white square regions. The IPF coloring in (c) is for both (a) and (b). $B F$ bainitic ferrite, $M A$ martensite/austenite constituent.

deconvoluted as the thermocouple readout cannot represent the whole gauge volume when temperature gradient exists.

The temperature uncertainty relates mainly to (1) the rapid cooling that is evident in Figures 3(c) and (d) which creates a temperature gradient witnessed as a non-linearity between $800{ }^{\circ} \mathrm{C}$ and $900{ }^{\circ} \mathrm{C}$; and (2) temperature regulation issue when the $\mathrm{He}$ gas cooling is turned off, which causes, e.g., a spike of $6{ }^{\circ} \mathrm{C}$ increase at the sixth second (Figures 6(e) and (f)). The temperature gradients in the literature where similar setups have been used ranges from $11{ }^{\circ} \mathrm{C}$ to $50{ }^{\circ} \mathrm{C}$ when cooling rates are between 100 and $200{ }^{\circ} \mathrm{C} \mathrm{s}^{-1}$. Such temperature gradient will not significantly affect the comparison of transformation kinetics and carbon diffusion between different isothermal temperatures. On the other hand, the minor changes of the ferrite lattice parameter due to changes in carbon content are only marginally larger than the effect of the minor temperature changes. Thus, more accurate measurements are needed to make quantitative conclusions for bcc. Furthermore, some empirical equations proposed only apply to alloys with higher carbon content, ${ }^{[36]}$ and some other equations suggest that the bcc lattice parameter is barely affected by the minor 

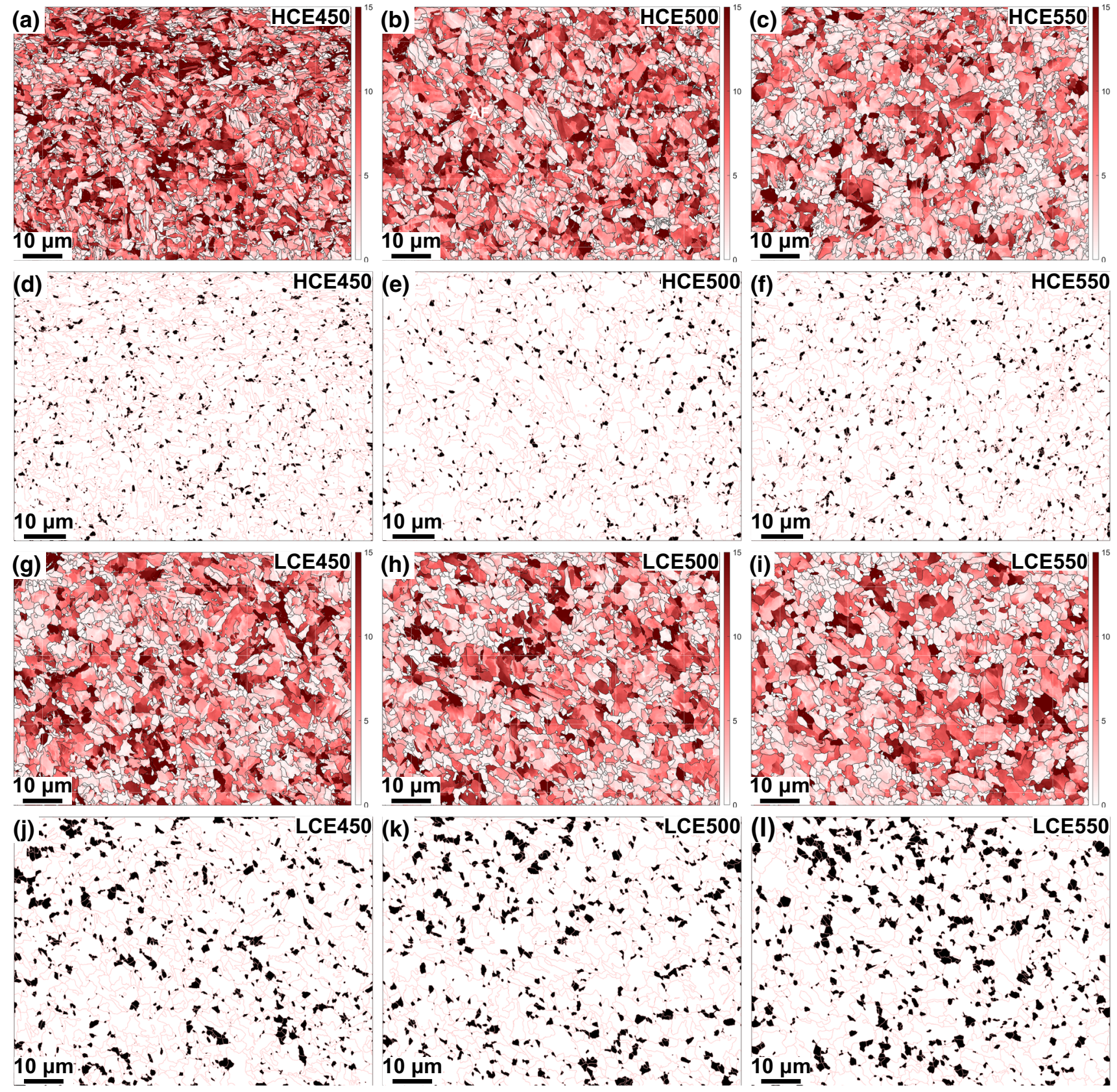

Fig. 9-EBSD maps showing misorientations to the mean misorientation within each grain, $(a$ to $c$ ) for HCE450, HCE500, and HCE550, respectively, and ( $g$ to $i$ ) for LCE450, LCE500, and LCE550, respectively; distribution of polygonal ferrite grains (black), $(d$ to $f$ ) in HCE450, HCE500, and HCE550, respectively, and ( $j$ to $l$ ) in LCE450, LCE500, and LCE550, respectively.

carbon content variations, since solubility of carbon in ferrite is so low. ${ }^{[37]}$ Therefore, the bcc lattice expansion/contraction due to changes in carbon content is expected to be small.

Before widely applying these types of measurements on low-alloy steel, a suggested further improvement is to use hollow tube-like thin-walled samples to increase the cooling rate so that the setup can replicate all technically relevant thermal cycles. It should be noted that the cooling rates applied here are similar to high industrial cooling rates, but it is of scientific interest to be able to better target specific transformations with perfect control of the heat treatment, e.g., by keeping an isothermal temperature throughout the whole austenite decomposition process also in the case of lean steels. The simultaneous application of small-angle scattering (SAS) can also help to investigate the kinetics of carbide formation in detail, which would be highly interesting.

\section{B. Austenite Decomposition Kinetics}

The austenite decomposition and accompanied carbon diffusion can be divided into three stages according to Figures 4 and 6: (1) formation of polygonal ferrite 


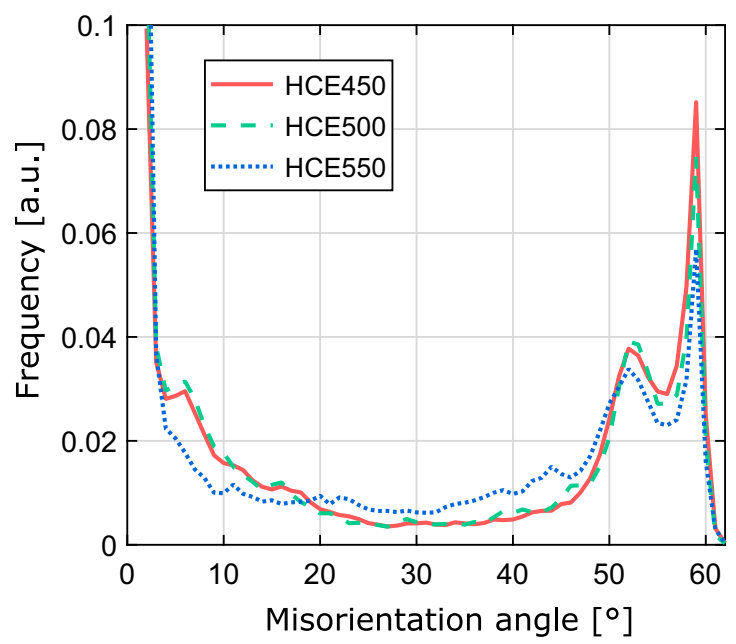

(a)

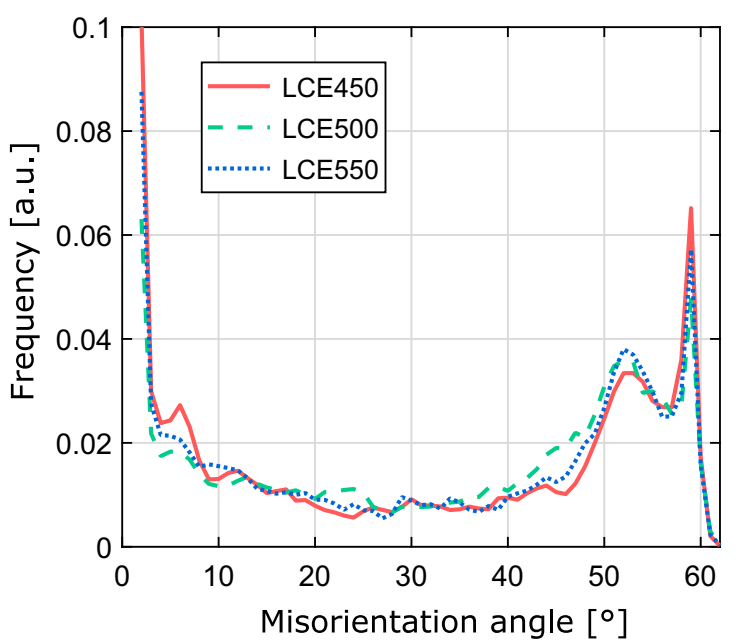

(b)

Fig. 10-Boundary misorientation frequency in (a) HCE samples, (b) LCE samples.

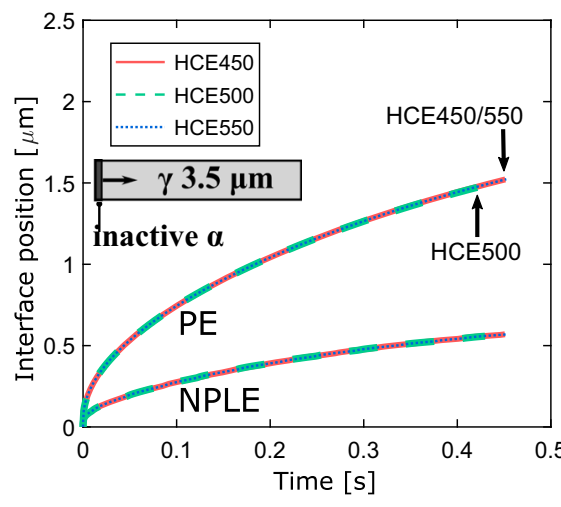

(a)

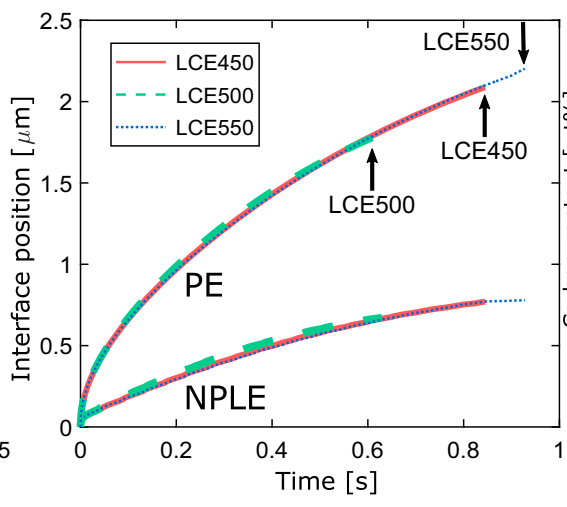

(b)

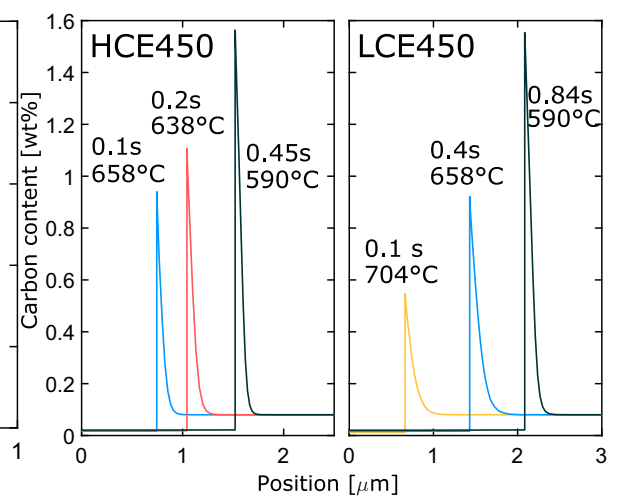

(c)

Fig. 11-DICTRA simulation of the formation of polygonal ferrite formation during initial quenching: $(a, b)$ interface position simulated with LE and PE conditions for HCEs and LCEs, respectively; arrows indicate the time when Bs-ML $\left(590{ }^{\circ} \mathrm{C}\right)$ is reached; $(c)$ carbon content profile at the ferrite/austenite interface for HCE450 and LCE450, respectively.

during initial cooling; (2) formation of bainite during initial cooling and isothermal holding; (3) austenite decomposition during prolonged heat treatment.

1. Formation of polygonal ferrite during initial cooling The polygonal ferrite volume fractions determined from HEXRD and EBSD results are in reasonable agreement as shown in Table III. Both methods indicate that the amount of polygonal ferrite formed is higher in LCEs than in HCEs, and for HCEs the amount is generally low. Comparing LCE samples, LCE450 and LCE500 appear to have similar amount of polygonal ferrite, whereas the polygonal ferrite in LCE550 appears to be higher. It should though be kept in mind that the HEXRD results rely on the calculated Bs temperatures. The difference in the calculated Bs between the two models Bs-TD and Bs-ML is about $50{ }^{\circ} \mathrm{C}$. Moreover, the construction of Bs models utilizes data acquired mainly from isothermal heat treatments, i.e., the effect of cooling rate on the bainitic transformation-start temperature ${ }^{[38,39]}$ is not considered.
The more rapid formation of polygonal ferrite found in LCEs compared to HCEs is associated with less alloying addition, in other words, lower carbon equivalent ${ }^{[17,40]}$ resulting in lower hardenability. In this study, the LCEs have lower $\mathrm{Cr}$, Mo, and $\mathrm{Nb}$ but higher $\mathrm{Si}$ content compared to the HCEs. Nb addition may affect the transformation kinetics via segregation to the phase interface and grain refinement through $\mathrm{NbC}$. $\mathrm{Nb}$ segregation to the phase interface resulting in retarded transformation kinetics has been reported, ${ }^{[41,42]}$ while grain refinement due to $\mathrm{NbC}$ promotes the transformation. ${ }^{[43]}$ Due to the low austenitization temperature and short austenitization time in the present study, the $\mathrm{NbC}$ remained undissolved leading to negligible $\mathrm{Nb}$ dissolved in the matrix and coarse carbides unable to significantly affect grain growth, i.e., both grades were found to have similar prior austenite grain size. Therefore, the effect of $\mathrm{Nb}$ on the formation of polygonal ferrite is concluded to be negligible in the present study. On the other hand, $\mathrm{Cr}$, $\mathrm{Mo}$, and $\mathrm{Si}$ retard the austenite decomposition by decreasing the driving force for formation of ferrite ${ }^{[44-46]}$ 
and increasing the activation energy for carbon diffusion. ${ }^{[47]}$ The coefficients for different elements according to Eq. [1] indicate that $\mathrm{Cr}$ and Mo have greater influence on transformation kinetics than $\mathrm{Si}$. The DICTRA simulations showed that when neglecting the Mo addition the transformation kinetics between the two materials are comparable (see the Supplementary Figure S-3). Therefore, it is suggested that the main contribution to the retardation of the formation of polygonal ferrite in HCE as compared to LCE is the Mo addition in the HCE alloy.

\section{Formation of bainite during cooling and isothermal holding}

The bainite transformation stage includes both continuous cooling and isothermal transformation, and the transformation kinetics is better illustrated as a transformation rate for HCEs and LCEs shown in Figure 12. For LCE samples, the transformation occurs mostly during continuous cooling, and the transformation rates for all LCE samples in Figure 12(b) are almost identical before the isothermal temperatures are reached, despite the slightly different cooling conditions and the formation of about 0.03 higher volume fraction of polygonal ferrite in LCE550. Ravi et al. ${ }^{[48]}$ and Quidort et al. ${ }^{[49]}$ observed that the bainitic transformation can be accelerated by ferrite volume fraction larger than 0.05 due to an increased number of nucleation sites provided by austenite/ferrite interface, whereas Zhu et al. observed a retardation effect due to local enrichment of $\mathrm{C}$ and $\mathrm{Mn}$ at the austenite/ferrite interface that reduces the chemical driving force. ${ }^{[50]}$ The materials investigated by Ravi et al. ${ }^{[48]}$ Quidort et al. ${ }^{[49]}$ and Zhu et al. ${ }^{[50]}$ have much higher carbon contents, larger prior austenite grain sizes, different isothermal heat treatment conditions, and much slower transformation kinetics than LCE.
Due to the rapid cooling and fast transformation kinetics in the present study, the width of the $\mathrm{C}$ enrichment at the austenite/ferrite interface predicted in Figure 11 is much less than that predicted by $\mathrm{Zhu}$ et al. ${ }^{[5]}$ Therefore, the retardation effect caused by the chemical gradient should be minor. Although it is difficult to quantify the polygonal ferrite/austenite interface, its acceleration effect is suggested to be minor as well, considering the identical curves for the different LCE samples in Figure 12(b).

It is also interesting to note that the transformation rate curves shown in Figure 12 are continuous where the transition from polygonal ferrite formation to bainitic ferrite formation occurs during continuous cooling. The formation of polygonal ferrite is closer to PE condition according to the DICTRA simulation due to the rapid cooling and thus the growth rate is mainly affected by the diffusion of carbon. Furthermore, both polygonal ferrite and Widmanstätten ferrite, here denoted bainitic ferrite and not distinguished from the ferrite formed during the bainitic transformation, can be regarded as proeutectoid transformation products where the bainitic ferrite can nucleate and grow from the polygonal ferrite. ${ }^{[51]}$ It is speculated that the smooth increase in transformation rate from polygonal ferrite to bainitic ferrite observed, e.g., in LCE, might indicate that the growth of bainitic ferrite is also controlled by carbon diffusion. It should, however, be noted that it cannot be ignored that the smooth transition could also be related to the slightly inhomogeneous temperature in the sample, minor segregations, and also a continuous nature of the change of one transformation to another.

For HCEs, the polygonal ferrite volume fraction is low and the main transformation takes place during the isothermal stage, and the bainite transformation is clearly temperature dependent showing an increased

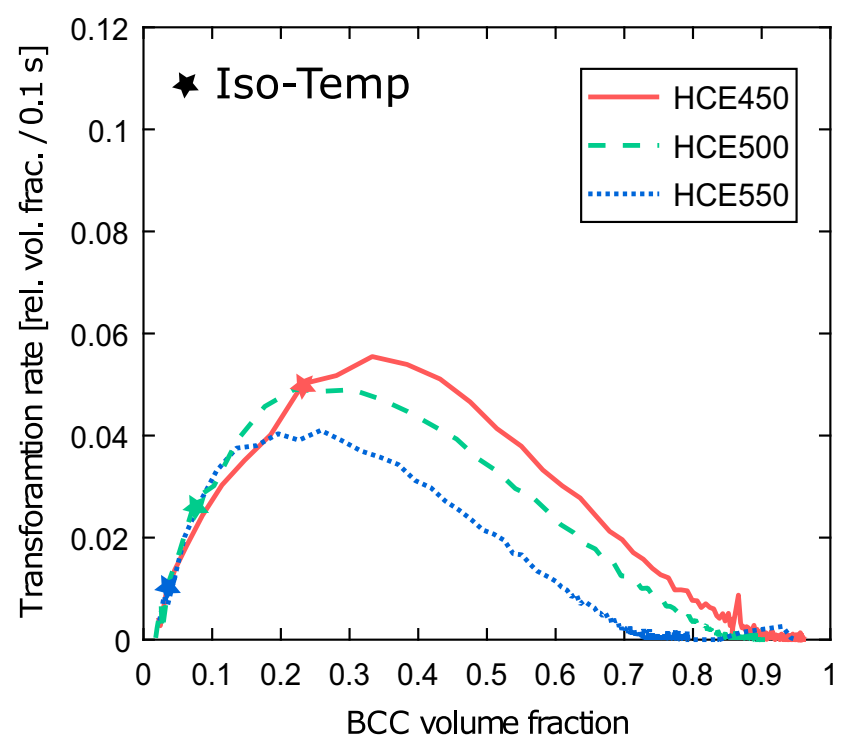

(a)

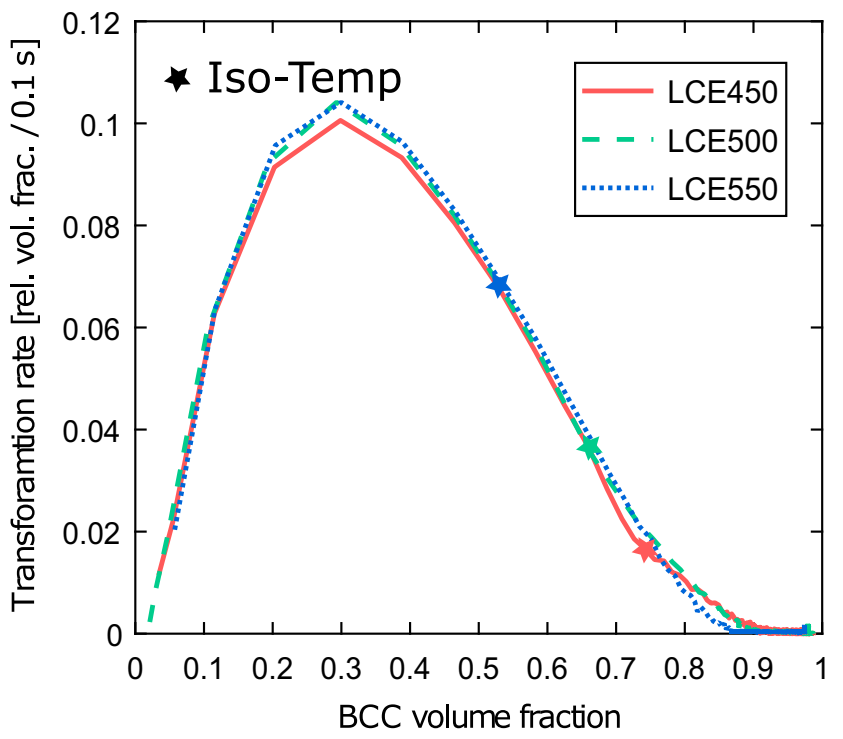

(b)

Fig. 12-The transformation rate, i.e., the derivative of volume fraction with respect to time, for $(a)$ HCEs and $(b)$ LCEs. The stars represent the volume fraction of polygonal ferrite and bainitic ferrite when the temperature reaches designated isothermal temperature. 
transformation rate with lowering temperature (Figure 12(a)). This indicates that all three isothermal temperatures are on the upper half of the C-curve in the TTT diagram approaching the maximum transformation rate, i.e., nose of the $\mathrm{C}$-curve as the temperature is lowered.

Compared to LCEs, HCEs have more distinctive incomplete transformation. This behavior may be an effect of the Mo addition as reported in previous experimental studies. ${ }^{[46,52]}$ It has been proposed that the stasis is caused by Mo segregation to the interface, causing solute drag effect (SDE), ${ }^{[4]}$ but another study has shown that Mo segregation occurs after the transformation stasis. ${ }^{[52]}$ Therefore, further studies are required to fully understand the mechanism of transformation stasis and the effect of Mo in these alloys.

The carbon enrichment in the retained austenite becomes prominent during the isothermal holding stage. In LCEs, carbon enrichment in austenite initiates earlier at higher isothermal temperatures as shown in Figure 6(b). The carbon content in the austenite in LCEs peaks at higher values than in HCEs. This is because a higher fraction of ferrite provides more carbon atoms to the austenite. Additionally, LCE steel has higher $\mathrm{Si}$ addition that may retard the carbide formation and lead to more carbon enrichment in retained austenite. Since the carbon content in the austenite is continuously increasing and only a few carbides are observed between the bainitic ferrite laths, carbide formation at this stage is insignificant.

\section{Prolonged heat treatment stage}

During the prolonged heat treatment, the decrease in austenite carbon content indicates the carbon depletion caused by carbide formation is significant. In the meantime, the austenite decomposition during this stage is more prominent at higher transformation temperature (Figures 4(a) and (b)). SEM images in Figure 7 show that at lower temperatures carbides are mostly observed between bainitic ferrite laths and packets, which suggests that they form during the last part of the bainitic transformation through a degenerated eutectoid transformation. Whereas at higher temperature, in addition to bainite, degenerate pearlite is also observed, which has also previously been reported by, e.g., Takayama et al. ${ }^{[16]}$ The high carbon content in the austenite retards subsequent decomposition and as shown in Figure 6, the carbon content in the austenite is lower at higher temperatures in accordance with $\mathrm{PE}$ conditions as also shown in Figure 11. Therefore, the amount of retained austenite with lower stability that can transform to martensite during final quenching is much higher in HCE550 than in HCE 500 and HCE 450.

\section{CONCLUSIONS}

- The austenite decomposition in two commercial high-strength low-alloy steels is investigated using in-situ high-energy X-ray diffraction during rapid cooling for the first time. The experimental condition mimics real heat treatment conditions and reveals the austenite decomposition to polygonal ferrite, pearlite, bainite, and martensite and the redistribution of carbon to the austenite phase.

- The steel with main composition Fe-0.08C-1.7Mn-0.403Si-0.303Cr experiences substantial austenite decomposition during cooling at a cooling rate of $280{ }^{\circ} \mathrm{C} \mathrm{s}^{-1}$. The main transformation products are polygonal ferrite and bainite and the transformation rate is observed to change continuously with decreasing temperature.

- In the steel with main composition Fe-0.08C-1.79Mn-0.182Si-0.757Cr-0.094Mo, polygonal ferrite formation during cooling is suppressed due to Mo addition. This leads to mainly bainitic transformation during isothermal holding at $450{ }^{\circ} \mathrm{C}$, $500{ }^{\circ} \mathrm{C}$, and $550{ }^{\circ} \mathrm{C}$. The transformation rate of the bainite is higher at lower temperature.

- DICTRA simulations indicate that the formation of polygonal ferrite during the initial cooling in both steels is closer to paraequilibrium than to negligible partitioning local equilibrium due to the rapid transformation kinetics, which is mainly controlled by carbon diffusion.

- During prolonged isothermal heat treatment at 450 ${ }^{\circ} \mathrm{C}$, $500{ }^{\circ} \mathrm{C}$, and $550{ }^{\circ} \mathrm{C}$ for both steels, carbide formation leads to carbon depletion in the austenite and further formation of bainitic ferrite. At the higher temperatures, formation of degenerate pearlite is also observed.

\section{ACKNOWLEDGMENTS}

The authors would like to acknowledge DESY for the provision of experimental facilities at P07, PETRA III (proposal I-20170966 EC), Helmholtz-Zentrum Geesthacht (HZG) for providing the dilatometer, and the HZG beamline scientist N. Schell for the assistance. The authors are also grateful towards Eric Nyman from SSAB for providing the materials, and Henrik Larsson for suggestions on DICTRA simulations. S. Lin would like to acknowledge the support from the China Scholarship Council (CSC) and Jernkontoret.

\section{FUNDING}

Open access funding provided by Royal Institute of Technology.

\section{OPEN ACCESS}

This article is licensed under a Creative Commons Attribution 4.0 International License, which permits use, sharing, adaptation, distribution and reproduction in any medium or format, as long as you give 
appropriate credit to the original author(s) and the source, provide a link to the Creative Commons licence, and indicate if changes were made. The images or other third party material in this article are included in the article's Creative Commons licence, unless indicated otherwise in a credit line to the material. If material is not included in the article's Creative Commons licence and your intended use is not permitted by statutory regulation or exceeds the permitted use, you will need to obtain permission directly from the copyright holder. To view a copy of this licence, visit http://creativecommons.org/licenses/by/4.0/.

\section{SUPPLEMENTARY INFORMATION}

The online version contains supplementary material available at https://doi.org/10.1007/s11661-021-06192-x.

\section{REFERENCES}

1. B.C. De Cooman: Curr. Opin. Solid State Mater. Sci., 2004, vol. 8, pp. 285-303.

2. M. Sudo, M. Higashi, H. Hori, T. Iwai, S. Kambe, and Z. Shibata: Trans. Iron Steel Inst. Jpn., 1981, vol. 21, pp. 820-27.

3. K. Sugimoto, J. Sakaguchi, T. Iida, and T. Kashima: ISIJ Int., 2000, vol. 40, pp. $920-26$.

4. Z.Z. Zhao, H.X. Yin, A.M. Zhao, Z.Q. Gong, J.G. He, T.T. Tong, and H.J. Hu: Mater. Sci. Eng. A, 2014, vol. 613, pp. 8-16.

5. M. Sudo, S. Hashimoto, and S. Kambe: Trans. Iron Steel Inst. Jpn., 1983, vol. 23, pp. 303-11.

6. B.S. Levy, M. Gibbs, and C.J. Van Tyne: Metall. Mater. Trans. A, 2013, vol. 44A, pp. 3635-48.

7. K. Rakha, H. Beladi, I. Timokhina, X. Xiong, S. Kabra, K.-D. Liss, and P. Hodgson: Mater. Sci. Eng. A, 2013, vol. 589 , pp. 303-09.

8. I.B. Timokhina, K.D. Liss, D. Raabe, K. Rakha, H. Beladi, X.Y. Xiong, and P.D. Hodgson: J. Appl. Crystallogr., 2016, vol. 49 , pp. $399-414$

9. S.D. Catteau, H.P. Van Landeghem, J. Teixeira, J. Dulcy, M. Dehmas, S. Denis, A. Redjaïmia, and M. Courteaux: J. Alloys Compd., 2015, vol. 658, pp. 832-38.

10. R.K. Dutta, R.M. Huizenga, M. Amirthalingam, A. King, H. Gao, M.J.M. Hermans, J. Sietsma, and I.M. Richardson: Metall. Mater. Trans. A, 2014, vol. 45A, pp. 218-29.

11. R. Rementeria, J.A. Jimenez, S.Y.P. Allain, G. Geandier, J.D. Poplawsky, W. Guo, E. Urones-Garrote, C. Garcia-Mateo, and F.G. Caballero: Acta Mater., 2017, vol. 133, pp. 333-45.

12. P. Kolmskog, A. Borgenstam, M. Hillert, P. Hedström, S.S. Babu, H. Terasaki, and Y.-I. Komizo: Metall. Mater. Trans. A, 2012, vol. 43A, pp. 4984-88.

13. S.S. Babu, E.D. Specht, S.A. David, E. Karapetrova, P. Zschack, M. Peet, and H.K.D.H. Bhadeshia: Metall. Mater. Trans. A, 2005, vol. 36 A, pp. $3281-89$.

14. F.G. Caballero, M.K. Miller, C. Garcia-Mateo, J. Cornide, and M.J. Santofimia: Scr. Mater., 2012, vol. 67, pp. 846-49.

15. P. Jacques, E. Girault, T. Catlin, N. Geerlofs, T. Kop, S. van der Zwaag, and F. Delannay: Mater. Sci. Eng. A, 1999, vols. 273-275, pp. 475-79.

16. N. Takayama, G. Miyamoto, and T. Furuhara: Acta Mater., 2018, vol. 145 , pp. $154-64$

17. N. Yurioka: ISIJ Int., 2001, vol. 41, pp. 566-570.

18. A. Stormvinter, A. Borgenstam, and J. Agren: Metall. Mater. Trans. A, 2012, vol. 43A, pp. 3870-79.
19. L. Leach, P. Kolmskog, L. Höglund, M. Hillert, and A. Borgenstam: Metall. Mater. Trans. A, 2018, vol. 49A, pp. 4509-20.

20. M. Rahaman, W. Mu, J. Odqvist, and P. Hedström: Metall. Mater. Trans. A, 2019, vol. 50A, pp. 2081-2091.

21. A.P. Hammersley, S.O. Svensson, and A. Thompson: Nucl. Instrum. Methods Phys. Res. Sect. A, 1994, vol. 346, pp. 312-21.

22. A.P. Hammersley, S.O. Svensson, M. Hanfland, A.N. Fitch, and D. Häusermann: High Press. Res., 1996, vol. 14, pp. 235-48.

23. G. Esteves, K. Ramos, C.M. Fancher and J.L. Jones: LIPRAS: Line-Profile Analysis Software, 2017.

24. ASTM International Standard A. E975-13, West Conshohocken, 2013.

25. N. van Dijk, A. Butt, L. Zhao, J. Sietsma, S. Offerman, J. Wright, and S. van der Zwaag: Acta Mater., 2005, vol. 53, pp. 5439-47.

26. K. Zhu, D. Barbier, and T. Iung: J. Mater. Sci, 2013, vol. 48, pp. 413-23.

27. S.M.C. van Bohemen: Scr. Mater., 2013, vol. 69, pp. 315-18.

28. F. Bachmann, R. Hielscher, and H. Schaeben: Ultramicroscopy, 2011, vol. 111, pp. 1720-33.

29. A. Gazder, F. Al-Harbi, H. Spanke, D. Mitchell, and E. Pereloma: Ultramicroscopy, 2014, vol. 147, pp. 114-32.

30. J.-O. Andersson, T. Helander, L. Höglund, P. Shi, and B. Sundman: Calphad, 2002, vol. 26, pp. 273-12.

31. A. Borgenstam, L. Höglund, J. Agren, and A. Engström: J. Phase Equilibria., 2000, vol. 21, pp. 269-80.

32. H. Larsson and L. Höglund: Calphad, 2009, vol. 33, pp. 495-501.

33. S. Shrestha, A. Breen, P. Trimby, G. Proust, S. Ringer, and J. Cairney: Ultramicroscopy, 2014, vol. 137, pp. 40-47.

34. P. Cizek, B. Wynne, C. Davies, and P. Hodgson: Metall. Mater. Trans. A, 2014, vol. 46A, pp. 407-25.

35. D.R. Black, D.A. Windover, A. Henins, J.J. Filliben, and J.P. Cline: Powder Diffr., 2011, vol. 26, pp. 155-58.

36. L. Cheng, A. Böttger, Th.H. de Keijser, and E.J. Mittemeijer: Scr. Metall. Mater., 1990, vol. 24, pp. 509-14.

37. M. Onink, C.M. Brakman, F.D. Tichelaar, E.J. Mittemeijer, S. van der Zwaag, J.H. Root, and N.B. Konyer: Scr. Metall. Mater., 1993, vol. 29, pp. 1011-16.

38. I.A. Yakubtsov and J.D. Boyd: Mater. Sci. Technol., 2001, vol. 17, pp. 296-301.

39. L. Jiang, R.K.W. Marceau, T. Dorin, P.D. Hodgson, and N. Stanford: J. Mater. Sci., 2019, vol. 54, pp. 1769-84.

40. S.M. Chentouf, M. Jahazi, L.-P. Lapierre-Boire, and S. Godlin: Metallogr. Microstruct. Anal., 2014, vol. 3, pp. 281-97.

41. M.G. Mecozzi, J. Sietsma, and S. van der Zwaag: Acta Mater., 2006, vol. 54, pp. 1431-40.

42. T. Furuhara, T. Yamaguchi, G. Miyamoto, and T. Maki: Mater. Sci. Technol., 2010, vol. 26, pp. 392-97.

43. K.Hausmann, D.Krizan, K.Spiradek-Hahn, A.Pichler, and E.Werner: Mater. Sci. Eng., A, 2013, vol. 588, pp. 142-150.

44. T. Sourmail and V. Smanio: Acta Mater., 2013, vol. 61, pp. $2639-48$.

45. M. Zhou, G. Xu, J. Tian, H. Hu, and Q. Yuan: Metals, 2017, vol. 7, p. 7.

46. E.S. Humphreys, H.A. Fletcher, J.D. Hutchins, A.J. Garratt-Reed, W.T. Reynolds, Jr, H.I. Aaronson, G.R. Purdy, and G.D.W. Smith: Metall. Mater. Trans. A, 2004, vol. 35A, pp. 1223-35.

47. J. Kong and C. Xie: Mater. Des., 2005, vol. 27, pp. 1169-73.

48. A.M. Ravi, A. Kumar, M. Herbig, J. Sietsma, and M.J. Santofimia: Acta Mater., 2020, vol. 188, pp. 424-34.

49. D. Quidort and Y.J.M. Brechet: Acta Mater., 2001, vol. 49, pp. $4161-70$.

50. K. Zhu, H. Chen, J.-P. Masse, O. Bouaziz, and G. Gachet: Acta Mater., 2013, vol. 61, pp. 6025-36.

51. J. Yin, M. Hillert, and A. Borgenstam: Metall. Mater. Trans. A, 2017, vol. 48A, pp. 1425-43.

52. T. Furuhara, K. Tsuzumi, G. Miyamoto, T. Amino, and G. Shigesato: Metall. Mater. Trans. A, 2014, vol. 45A, pp. 5990-96.

Publisher's Note Springer Nature remains neutral with regard to jurisdictional claims in published maps and institutional affiliations. 